\title{
HERMESv3, a stand-alone multi-scale atmospheric emission modelling framework - Part 1: global and regional module
}

\author{
Marc Guevara, Carles Tena, Manuel Porquet, Oriol Jorba, and Carlos Pérez García-Pando \\ Earth Sciences Department, Barcelona Supercomputing Center, Barcelona, 08034, Spain \\ Correspondence: Marc Guevara (marc.guevara@bsc.es)
}

Received: 13 December 2018 - Discussion started: 7 January 2019

Revised: 10 April 2019 - Accepted: 23 April 2019 - Published: 14 May 2019

\begin{abstract}
We present the High-Elective Resolution Modelling Emission System version 3 (HERMESv3), an open source, parallel and stand-alone multi-scale atmospheric emission modelling framework that computes gaseous and aerosol emissions for use in atmospheric chemistry models. HERMESv3 is coded in Python and consists of a global_regional module and a bottom_up module that can be either combined or executed separately. In this contribution (Part 1) we describe the global_regional module, a customizable emission processing system that calculates emissions from different sources, regions and pollutants on a userspecified global or regional grid. The user can flexibly define combinations of existing up-to-date global and regional emission inventories and apply country-specific scaling factors and masks. Each emission inventory is individually processed using user-defined vertical, temporal and speciation profiles that allow obtaining emission outputs compatible with multiple chemical mechanisms (e.g. Carbon-Bond 05). The selection and combination of emission inventories and databases is done through detailed configuration files providing the user with a widely applicable framework for designing, choosing and adjusting the emission modelling experiment without modifying the HERMESv3 source code. The generated emission fields have been successfully tested in different atmospheric chemistry models (i.e. CMAQ, WRFChem and NMMB-MONARCH) at multiple spatial and temporal resolutions. In a companion article (Part 2; Guevara et al., 2019) we describe the bottom_up module, which estimates emissions at the source level (e.g. road link) combining state-of-the-art bottom-up methods with local activity and emission factors.
\end{abstract}

\section{Introduction}

Emission inputs of trace gases and aerosols play a key role in the performance of atmospheric chemistry models for air quality research and forecasting applications. Depending on the purpose of the application, an atmospheric chemistry model may be applied at global, regional or local (urban) scales. Similarly, the level of coverage and detail required for the emission input data will vary according to the type of study and modelling scale (e.g. Borge et al., 2014).

For global and regional modelling, emissions are typically estimated at country level (combining national statistics and technology-dependent emission factors) and then disaggregated using spatial proxies such as population density and land use. Different global and regional emission inventories are continuously being developed and made publicly available by research groups and international programs such as the Global Emissions Initiative (GEIA) (Frost et al., 2013). These inventories usually report total annuals per primary pollutant and source sector distributed over a rectangular grid at resolutions ranging from $1^{\circ}$ by $1^{\circ}$ to $0.1^{\circ}$ by $0.1^{\circ}$. The practical use of these inventories suffers from several problems. On the one hand, the reporting format is not directly compatible with the emission input requirements of atmospheric chemistry models as these typically ingest hourly and chemical species-based emissions over other grid projections and resolutions using specific file formats and conventions. On the other hand, there are substantial discrepancies in the total emissions, sectorial emission shares, spatial distribution and pollutant sources considered between the available inventories and therefore in their respective behaviour when used in atmospheric chemistry models (e.g. Granier et al., 2011; Trombetti et al., 2018; Saikawa et al., 2017). While having independent emission datasets instead of only one to- 
tally harmonized inventory is crucial from a science perspective, having the capacity to combine them and apply adjustment factors in a flexible and transparent way can be also of importance for air quality modelling studies. All in all, the incorporation of emission data into atmospheric chemistry models usually implies laborious programming in order to combine, adjust and adapt the original inventories to the model requirements.

Global and regional inventories are too imprecise for urban-scale modelling applications (e.g. Timmermans et al., 2013). Emission and activity factors lack specificity for the local conditions of interest (e.g. Guevara et al., 2014), and the spatial proxies used to allocate the emissions are of poor resolution and may not apply to certain emission processes (e.g. López-Aparicio et al., 2017). These inventories are, for example, limited when it comes to predicting and assessing the impact of emission reduction measures upon local air quality such as the change in speed limits (e.g. Baldasano et al., 2010 ) or the penetration of new vehicle technologies (e.g. Soret et al., 2014). Consequently, working at the urban scale requires dedicated local emission inventories combining activity data collected at a fine spatial scale (e.g. point source, road links, household) with bottom-up detailed emission algorithms that represent the different factors influencing the emission processes (e.g. vehicle speed, outdoor temperature).

In this paper and a companion paper (Guevara et al., 2019), we describe the newly developed High-Elective Resolution Modelling Emission System version 3 (HERMESv3). HERMESv3 is a multi-scale, open-source emission modelling framework that consists of two independent modules that can be either combined or executed separately: (i) the global_regional module and (ii) the bottom_up module. The global_regional module is a customizable emission processing system that calculates emissions from different sources, regions and pollutants on a user-specified global or regional model grid. The user can easily define combinations of existing global and regional emission inventories, which are individually processed using vertical, temporal and speciation profiles, and apply regional scaling factors and masks. The generated emission fields have been tested for different chemical mechanisms and atmospheric chemistry models, including CMAQ (Appel et al., 2017), WRF-Chem (Grell et al., 2005) and NMMB-MONARCH (Badia et al., 2017) models, and can easily be adapted to other models, grids or chemical mechanisms upon demand.

The bottom_up module is an emission model that can be used to estimate emissions at the source level (e.g. road link, industrial facility, crop type) and hourly level combining state-of-the-art estimation methods with local activity and emission factors along with meteorological data. This model covers the estimation of bottom-up emissions from point sources (e.g. power and manufacturing industries), road transport, residential combustion and agricultural activities (manure management, fertilizer application and crop operations), as well as the modelling of detailed emission scenar- ios for air quality planning studies. Besides the aforementioned atmospheric chemistry models, the emission outputs of this module are also adapted for their application with the R-LINE urban dispersion model (Snyder et al., 2013).

We conceive HERMESv3 as a flexible multi-scale modelling framework that allows integrating and combining different emissions estimation approaches, so that the emission related outputs can be as detailed and specific as possible for the different domains (global, regional or local) involved in the corresponding application.

The development of HERMESv3 is based on the knowledge acquired from previous versions of HERMES for Spain (Baldasano et al., 2008; Guevara et al., 2013), Europe (Ferreira et al., 2013) and Mexico City (Guevara et al., 2017) that have been developed at the Earth Sciences Department of the Barcelona Supercomputing Center (BSC) during the last decade. Other existing emission software such as HEMCO (Keller et al., 2014) and PREP-CHEM-SRC (Freitas et al., 2011) have also been taken as a reference for the development of HERMESv3.

In this paper (Part 1) we provide a description of the global_regional module (herein referred to as HERMESv3_GR). The bottom_up module is described in the companion paper (Part 2; Guevara et al., 2019). The paper is organized as follows. Section 2 describes the processing system and its main functionalities together with some illustrative examples of the outputs that can be generated with this tool. Section 3 describes some of the current implementations of HERMESv3_GR for air quality modelling. Finally, Sect. 4 presents the main conclusions of this work.

\section{Description of HERMESv3}

\subsection{Overview}

Figure 1 shows a schematic representation of the structure of HERMESv3_GR along with the execution workflow. HERMESv3_GR first defines the destination grid and selects the emission inventories (see Sect. 2.2), and the vertical, temporal and speciation profiles based on the specifications defined by the user in the general and emission inventory configuration files (see Sect. 2.3 and 2.4, respectively). During the initialization process, HERMESv3_GR automatically creates a set of auxiliary files that are subsequently used during the emission calculation process. These auxiliary files, including the output grid description, the time zones and the country mask, are specific to each new working domain and are stored by default after their creation so that they can be reused in subsequent executions. The emissions are calculated in four steps that are applied to each pollutant sector and species of the selected original emission inventories. These four steps include (i) the spatial regridding from source grid to destination grid (see Sect. 2.5.1), (ii) the mass distribution over model vertical layers (see Sect. 2.5.2), (iii) the temporal 
disaggregation (see Sect. 2.5.3), and (iv) the speciation mapping depending on the selected gas-phase and aerosol chemical mechanisms (see Sect. 2.5.4). The emission calculation can combine inventories that cover different geographic domains and/or emission sectors. To prevent spatial overlapping between inventories a masking functionality is included during the regridding phase. The user can define countryspecific masks that restrict the applicability of the original inventory to a given region and country-specific scaling factors. Once the emissions have been processed, HERMESv3_GR writes the output file following the requirements and conventions of the atmospheric chemistry model selected by the user in the general configuration file (see Sect. 2.5.5).

For each grid cell $x$ and vertical layer $l$ on the destination domain and requested output species $e$, HERMESv3_GR computes the output hourly emissions following Eq. (1).

$$
\begin{aligned}
E_{\text {out }}(x, l)_{e} & =\sum_{i=1}^{I} \sum_{s=1}^{S} \sum_{\bar{x}=1}^{\bar{X}}\left\{E_{\mathrm{in}}(\bar{x}) \cdot \mathrm{RF}(\bar{x}) \cdot \mathrm{VF}(\bar{x}, l)\right. \\
& \cdot \mathrm{TF} \cdot \mathrm{SF}\}_{\bar{e}, s, i}
\end{aligned}
$$

where $E_{\text {in }}(\bar{x})_{\bar{e}, s, i}$ is the input emission flux $\left(\mathrm{kg} \mathrm{m}^{-2} \mathrm{~s}^{-1}\right)$ of the species $\bar{e}$ and pollutant sector $s$ reported by inventory $i$ on the source grid cell $\bar{x} \operatorname{RF}(\bar{x})_{\bar{e}, s, i}$ is the remapping weight value from source grid cell $\bar{x}$ to the destination grid cell $x$ associated with species $\bar{e}$ and pollutant sector $s$ of inventory $i . \operatorname{VF}(\bar{x}, l)_{\bar{e}, s, i}$ is the vertical weight factor for layer $l$ and source grid cell $\bar{x}$ assigned to species $\bar{e}$ and pollutant sector $s$ of inventory $i$ (0 to 1$)$. $\mathrm{TF}_{\bar{e}, s, i}$ is the temporal weight factor $t$ assigned to species $\bar{e}$ and pollutant sector $s$ of inventory $i$. $\mathrm{SF}_{\bar{e}, s, i}$ is the speciation factor assigned to species $\bar{e}$ and pollutant sector $s$ of inventory $i$. The final $E_{\text {out }}(x, l)_{e}$ is the hourly emission for output species $e$ in destination grid cell $x$, layer $l$ and is the sum of (i) all $\bar{X}$ source grid cells $\bar{x}$ that contribute to destination grid cell $x$, (ii) all $S$ employed pollutant sources $s$ and (iii) all $I$ used emission inventories $i$. The units of the output emissions will vary according to the atmospheric chemistry model selected by the user.

$\operatorname{RF}(\bar{x})_{\bar{e}, s, i}$ and $\mathrm{TF}_{\bar{e}, s, i}$ are computed following Eqs. (2) and (3), respectively.

$$
\begin{aligned}
& \operatorname{RF}(\bar{x})_{\bar{e}, s, i}=W(\bar{x})_{i} \cdot\{\mathrm{MK}(\bar{x}) \cdot \operatorname{SC}(\bar{x})\}_{\bar{e}, s, i}, \\
& \operatorname{TF}_{\bar{e}, s, i}=\{M(m) \cdot D(d) \cdot H(h)\}_{\bar{e}, s, i},
\end{aligned}
$$

where $W(\bar{x})_{i}$ is the regridding weight value that describes how the source grid cell $\bar{x}$ contributes to the destination grid cell $x$ (0 to 1$)$. $\operatorname{MK}(\bar{x})_{\bar{e}, s, i}$ is the masking factor assigned to species $\bar{e}$ and pollutant sector $s$ of inventory $i$ on the source grid cell $\bar{x}(1$ or 0$)$. $\mathrm{SC}(\bar{x})_{\bar{e}, s, i}$ is the scaling factor assigned to species $\bar{e}$ and pollutant sector $s$ of inventory $i$ on the source grid cell $\bar{x} . M(m)_{\bar{e}, s, i}$ is the monthly factor for month $m$ assigned to species $\bar{e}$ and pollutant sector $s$ of inventory $i$ (0 to 12$). D(d)_{\bar{e}, s, i}$ is the daily factor for day $d$ assigned to species $\bar{e}$ and pollutant sector $s$ of inventory $i$ ( 0 to $28,29,30$ or 31 depending on the total number of days for month $m$ ). $H(h)_{\bar{e}, s, i}$ is the hourly factor for hour $h$ assigned to species $\bar{e}$ and pollutant sector $s$ of inventory $i$ ( 0 to 24 ).

\subsection{Emission data library and pre-processing}

Table 1 lists all the global and regional inventories currently considered in the HERMESv3_GR emission data library. On demand, new emission datasets can be added. At a global scale, the inventories proposed for anthropogenic emissions include the Air Pollutants and Greenhouse Gases Emission Database for Global Atmospheric Research (EDGAR v4.3.2_AP, Crippa et al., 2018; EDGARv4.3.2_VOC, Huang et al., 2017), the Community Emissions Data System (CEDS; Hoesly et al., 2018) and the datasets derived from the Task Force Hemispheric Transport of Air Pollution community (HTAPv2.2; Janssens-Maenhout et al., 2015) and the Evaluating the Climate and Air Quality Impacts of Short-Lived Pollutants project (ECLIPSEv5.a; Klimont et al., 2017). Also at a global scale, biomass burning emissions are provided by the Global Fire Assimilation System (GFASv1.2; Kaiser et al., 2012), whereas open burning of domestic waste and volcanic degassing emissions can be estimated using the inventories reported by Wiedinmyer et al. (2014) and Carn et al. (2017), respectively. Two European regional anthropogenic emission inventories are also considered, namely TNO-MACC_III (Kuenen et al., 2014) and the EMEP (Mareckova et al., 2017). The emission data library compiles gaseous $\left(\mathrm{NO}_{x} ; \mathrm{CO}\right.$; non-methane volatile organic compounds, NMVOC; $\mathrm{SO}_{x} ; \mathrm{NH}_{3}$ ) and particulate $\left(\mathrm{PM}_{10} ; \mathrm{PM}_{2.5}\right.$; black carbon, $\mathrm{BC}$; organic carbon, $\left.\mathrm{OC}\right)$ air pollutant emissions. Depending on the inventory, NMVOC emissions are reported as a single category (e.g. ECLIPSEv5.a), by individual species (e.g. GFASv1.2) or following the 25 species groups as proposed within the Global Emission Inventory Activity (GEIA) (Olivier et al., 1996) (e.g. EDGARv4.3.2_VOC). Most of the inventories are reported at the monthly level and include time series with multiple base years (past, present and future).

For each inventory, a specific pre-processing function has been developed to rewrite the original datasets on a common format. All the gridded emission inventory input files used by HERMESv3_GR (i) are in the Network Common Data Form (NetCDF) format (http://www.unidata.ucar.edu/ software/netcdf/, last access: May 2019), (ii) adhere to the Climate and Forecast (CF1.6) Metadata Conventions, (iii) include information on the cell centroids, boundary coordinates and cell areas of the working domain (needed for the conservative remapping; see Sect. 2.5.1), (iv) report emissions in the same units $\left(\mathrm{kg} \mathrm{m}^{-2} \mathrm{~s}^{-1}\right)$, (v) follow a unique pollutant naming convention (e.g. "nox_no2" for $\mathrm{NO}_{x}$ emissions expressed as $\mathrm{NO}_{2}$ and "nox_no" for $\mathrm{NO}_{x}$ emissions expressed as NO), and (vi) follow a unique file data storage convention (Sect. 2.4). Exceptionally, point source emission 


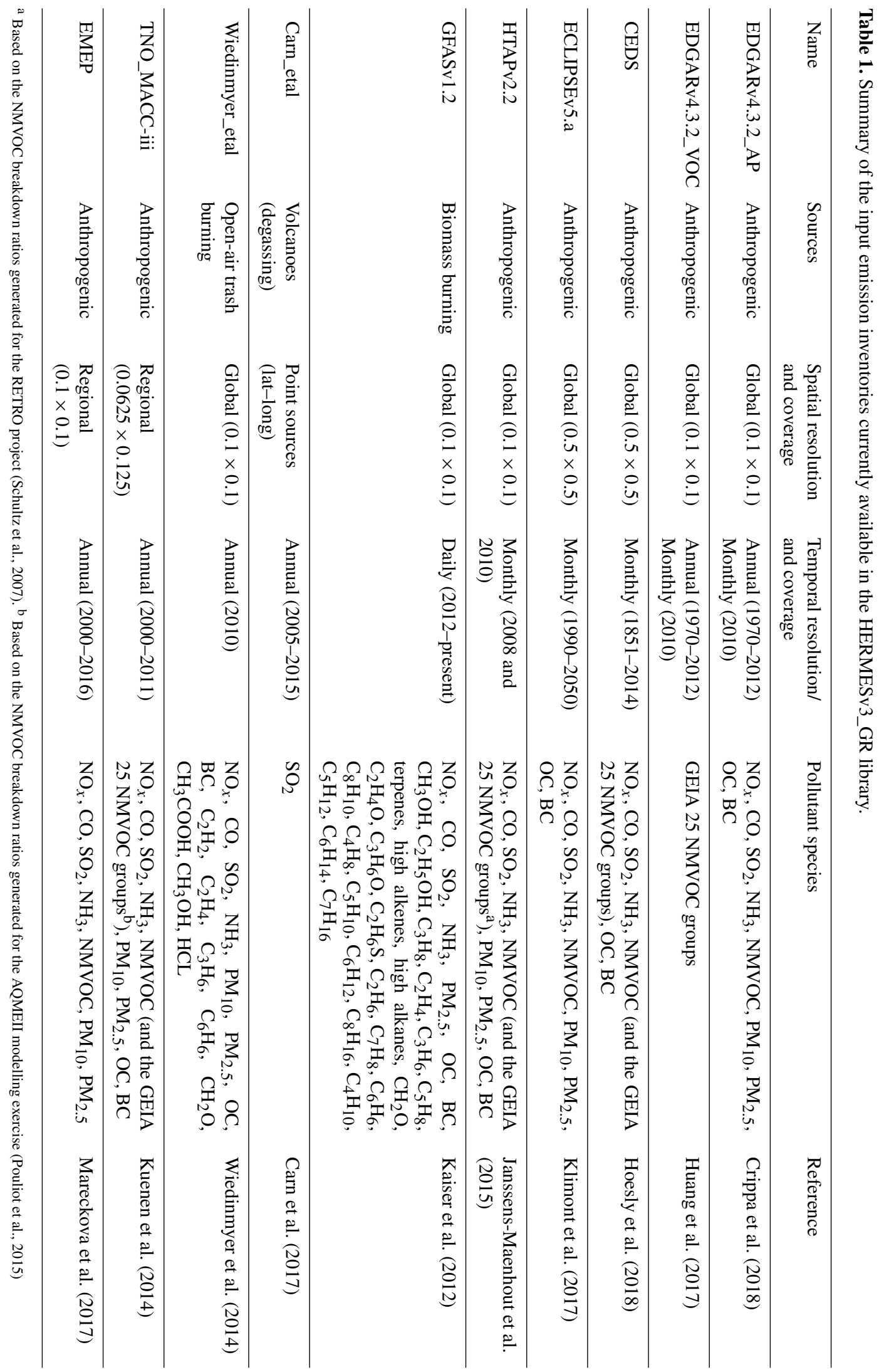




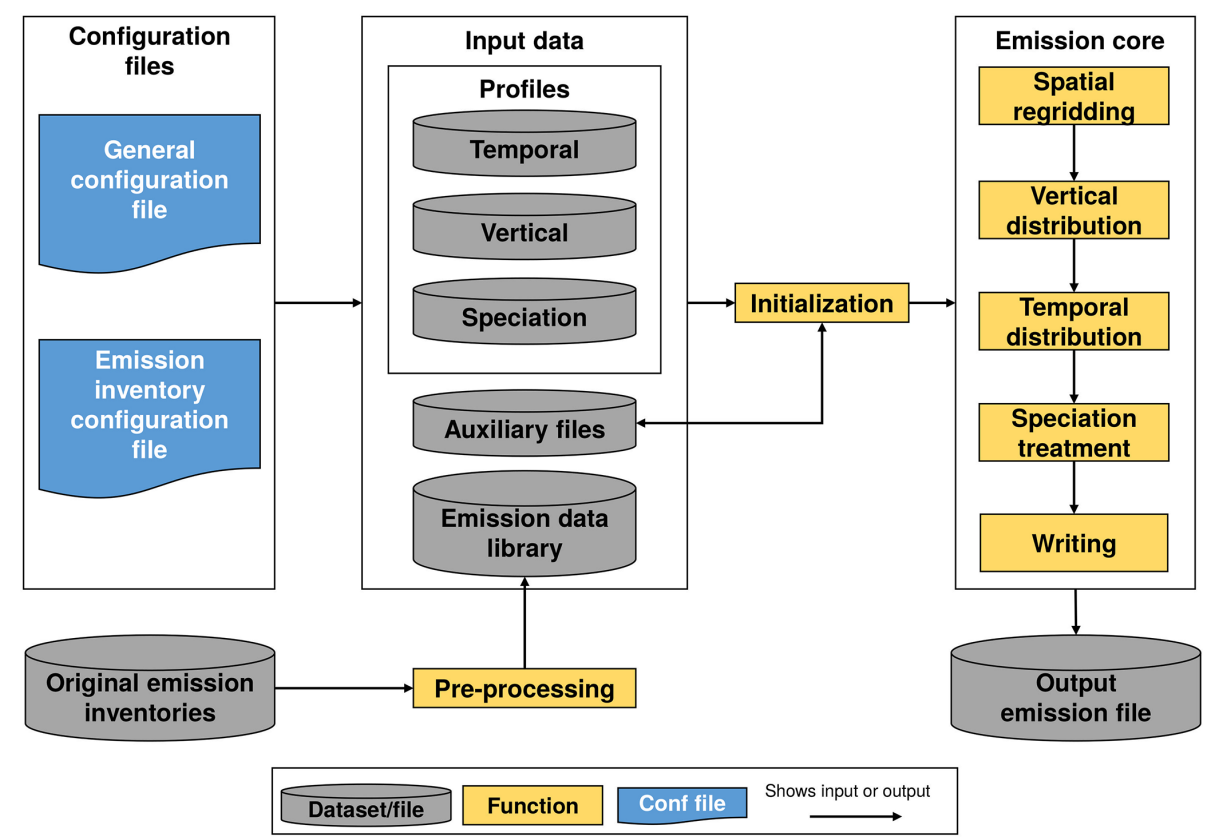

Figure 1. Schematic representation of the general structure of HERMESv3_GR.

inventories (e.g. volcanic degassing emissions) are stored in CSV files that include information on the name of each source (e.g. name of the volcanoes), geographic coordinates, altitude of injection of the emissions (in metres) and total amount of annual emissions $\left(\mathrm{kg} \mathrm{s}^{-1}\right)$. For this type of inventory, no pre-processing function is needed and the user can directly provide the data in the required format.

All the pre-processing functions used to transform the original inventories are included in the HERMESv3_GR code repository. It is important to note that the original gridded emission inventories are not stored inside the HERMESv3_GR database and that users need to download them from the corresponding data provider's platform (e.g. EDGAR inventories are obtained from http://edgar.jrc.ec. europa.eu/, last access: May 2019). This decision is based on the fact that (i) some of the emission inventories that HERMESv3_GR can process cannot be passed on to third parties without the data provider's consent and (ii) we believe it is good practice that users access the original files through the official source of information, so that the data providers can monitor the usage of their datasets. With the aim of helping the users, the HERMESv3_GR wiki contains a section that provides information on each emission inventory, including the official downloading website or contact person (see Sect. 5). This information is also included in a README section inside each pre-processing function.

HERMESv3_GR only includes anthropogenic, biomass burning and volcano emission inventories. Natural emissions such as biogenic NMVOCs, mineral dust aerosols, ocean DMS (dimethyl sulfide) or lightning, and soil NO, which have functional dependencies on meteorological variables, are assumed to be calculated online during the execution of the corresponding atmospheric chemistry model (e.g. the NMMB-MONARCH dust module; Pérez et al., 2011) or using specific emission models (e.g. MEGANv2.1; Guenther et al., 2012).

\subsection{General configuration file}

The general configuration options (e.g. start and end date, output file name, working domain description) can be passed to HERMESv3_GR via a configuration file, arguments or a combination of both. The arguments passed by command line take priority over the ones that appear in the configuration file.

The general configuration file is divided into four different sections (see example in Appendix A).

1. General: this section defines the main paths of the processing system (i.e. input, output, data), the name of the output emission file and time step configuration parameters, including start and end dates, temporal resolution (i.e. monthly, daily, hourly), and number and frequency of time steps (e.g. 24 time steps every 3 h).

2. Domain selection: this section defines the working grid where emissions will be calculated (e.g. spatial extension, horizontal and vertical description). Currently, HERMESv3_GR can calculate emissions on grids with the following map projections: regular lat-long for global domains and rotated lat-long and Lambert conformal conic for regional domains. Other coordinate systems and combinations (e.g. regular lat-long for re- 
gional domains) could be added upon request. In this section of the configuration file, the user also selects the format of the output emission file. Currently, HERMESv3_GR is able to write NetCDF emission output files following the CMAQ, WRF-Chem or NMMBMONARCH conventions and can easily be extended to other projections and atmospheric chemistry model conventions.

3. Emission inventory configuration: this section defines the path to the file describing the configuration of the emission inventories (see Sect. 2.4).

4. Profiles selection: this section defines the profile files that will be applied to perform the vertical distribution, temporal disaggregation and speciation treatment of the original emission inventories (see Sect. 2.5.1 to 2.5.4).

\subsection{Emission inventory configuration file}

The emission inventory configuration file allows the user to select the base emission inventories, pollutant sectors and species to combine and overlay for their simulations and to choose the corresponding temporal, vertical and speciation profiles and optional scaling and masking factors that will be applied to the original emissions for their adaptation to the CTM requirements.

Each line of the emission inventory configuration file belongs to a specific emission inventory, pollutant sector and pollutant species group, for which the user can define

- country-specific scaling factors that multiply the original emissions;

- country-specific masks that restrict the applicability of the original inventory to a given region;

- a vertical profile to distribute the original emissions across the vertical layers of the working domain;

- a monthly, daily and hourly profile to temporally disaggregate the original emissions;

- a speciation profile to map the original pollutants species to a specific gas-phase and aerosol chemical mechanism.

Figure 2 shows five examples of emission inventory configuration files and the resulting emission outputs calculated by HERMESv3_GR. The first column ("ei") indicates the name of the emission inventory, followed by the name of the pollutant sector ("sector"), the reference year of the emission inventory ("ref_year"), the requested pollutant species to be computed ("pollutants") and a field that indicates if this sector is activated or not ("active", 0 or 1). HERMESv3_GR combines all this information in order to select the corresponding file from the emission data library. In the first example (Fig. 2a), we selected the 2010 HTAPv2.2 OC trans- port emissions, while in the second one (Fig. 2b) this inventory is combined with OC biomass burning emissions from GFASv1.2. The resulting output shows an increase in emissions in those areas typically affected by forest fires (e.g. central Africa).

The following two columns of the configuration file are optional parameters that can be used to define countryspecific scaling factors that multiply the original emissions ("factor_mask") and country-specific masks that restrict the applicability of the original emissions to the defined region ("regrid_mask"). Country-specific scaling factors are defined combining the ISO 3166-1 alpha-3 country code of the targeted country (https://unstats.un.org/unsd/tradekb/ knowledgebase/country-code, last access: May 2019) with a numerical factor. Scaling factors for more than one country need to be separated by a comma. Our third example (Fig. 2c) shows the original 2010 HTAPv2.2 OC transport emissions scaled by a factor of 5 in China and 0.5 in India (CHN 5, IND 0.5). On the other hand, country-specific masks are defined using the ISO 3166-1 alpha-3 country code preceded by either a "+" sign, which restricts the applicability of the inventory only to the targeted country, or a "-" sign, which restricts the applicability of the inventory to all the countries except the targeted one. The masks defined by the user can include more than one country. In the fourth example (Fig. 2d), the HTAPv2.2 OC transport emissions are restricted to all countries except China and India (- CHN,IND), while in the fifth example (Fig. 2e) the OC transport emissions from ECLIPSEv5a are only applied to China and India (+ CHN,IND).

The column "frequency" defines the temporal resolution of the inventory (i.e. annual, monthly, daily). The column "path" defines the root path of the emission files of each inventory. For all inventories, the root path consists of the common "〈data_path〉" defined in the general configuration file followed by the name of the institution providing the inventory, the name of the inventory and the temporal frequency. As shown in the first example, the root path of the HTAPv2.2 emission files is "/data_path $/$ jrc/htapv22/monthly_mean".

The alphanumeric codes specified in columns "p_vertical", "p_month" "p_day" "p_hour" and "p_speciation" refer to the vertical, monthly, daily, hourly and speciation profile IDs assigned to process the original emissions. All the codes are cross-referenced with text files where the vertical, temporal and speciation numerical factors are defined. As shown in the first example, the "p_hour" field allows the user to define specific diurnal profiles for weekdays, Saturdays and Sundays, which may be of relevance for certain pollutant sectors such as road transport (e.g. Mues et al., 2014). For the GFASv1.2 biomass burning emissions (second example), the "p_vertical" field is not filled with a vertical profile ID but with two parameters that define (i) the maximum altitude of the fire plume injection height ("method") and (ii) how the emissions are distributed across the layers below this maximum height ("approach") 


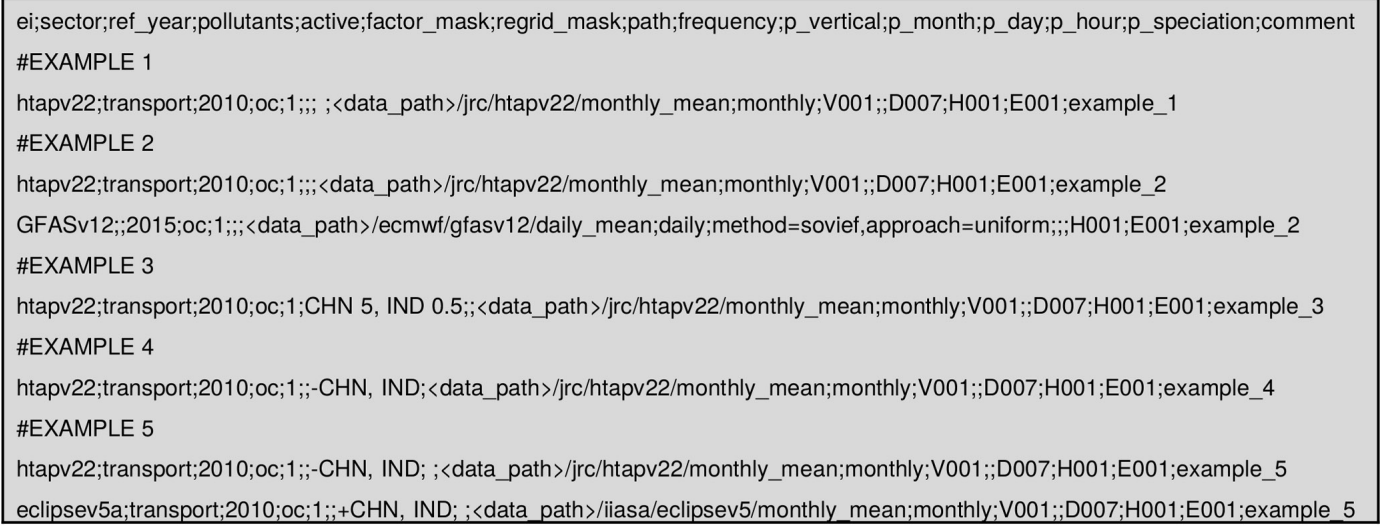

HTAP road transport

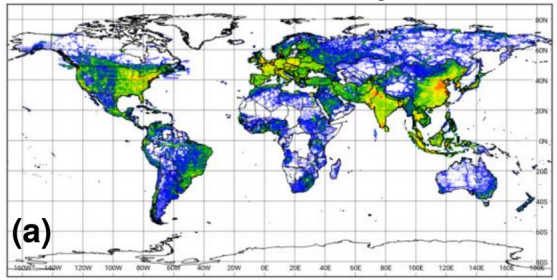

HTAP road transport (China $\times 5$, India $\times 0.5)$

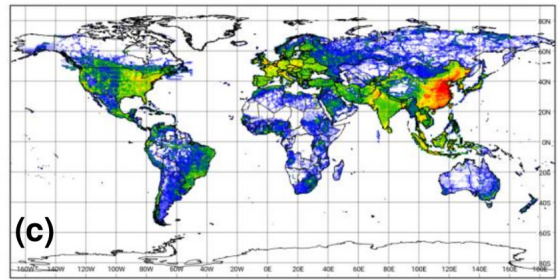

HTAP road transport + GFAS

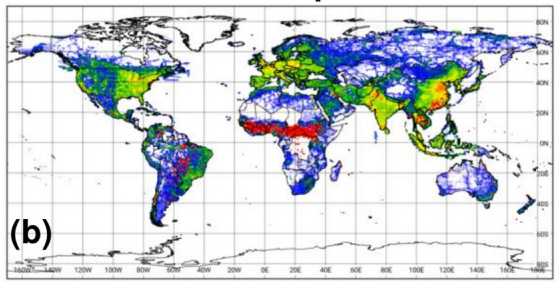

HTAP road transport (China $\times 0$, India $\times 0$ )

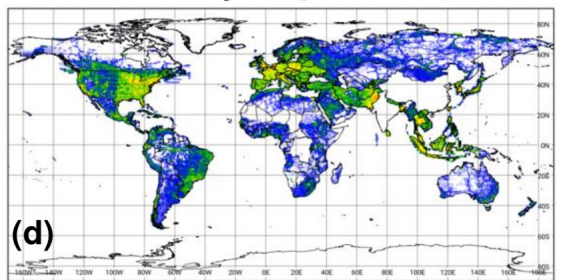

ECLIPSE (China, India) + HTAP (rest) road transport

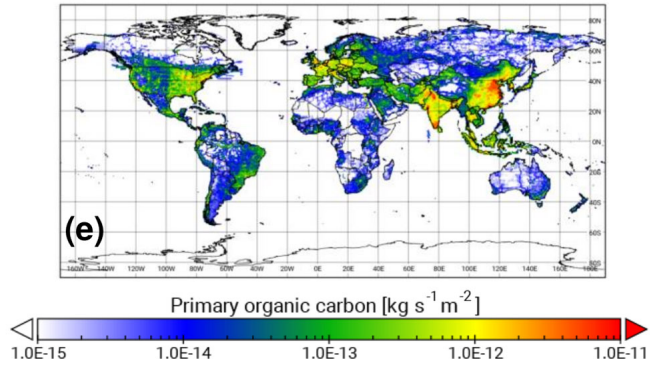

Figure 2. Examples of organic carbon global emission outputs regridded onto a $0.5^{\circ} \times 0.7^{\circ}$ global regular lat-long domain obtained with HERMESv3_GR using five different versions of the emission inventory configuration file: HTAP road transport (a), HTAP road transport + GFAS (b), HTAP road transport with scaling factors over China (5) and India (0.5) (c), HTAP road transport masking out China and India (d), and ECLIPSE road transport (China and India) + HTAP road transport (rest of countries) (e). The corresponding emission inventory configuration files used in each example are shown at the top.

(see Sect. 2.5.2). Finally, the "comment" column is an optional field in which the user can add an observation.

\subsection{Emission core module}

The following sections describe the main functionalities of HERMESv3_GR, namely the spatial, vertical, temporal and speciation processing of the original emissions and the writing of the output file.

\subsubsection{Spatial regridding}

This function regrids the selected inventories from their original source grid to the user-defined destination grid. The regridding process consists of two steps. The first step uses the Earth System Modeling Framework (ESMF) regrid weight generation application (Hill et al., 2004) to calculate a regridding weight matrix that describes how points in the source 
grid contribute to points in the destination grid. The regridding method is first-order conservative, which means that it preserves the integral of the source field across the regridding. The weight for a particular source cell $i$ and destination cell $j\left(W_{i, j}\right)$ is based on the ratio of the source cell area overlapped with the corresponding destination cell area (Eq. 4):

$W_{i, j}=f_{i, j} \cdot \frac{\mathrm{AS}_{i}}{\mathrm{AD}_{j}}$,

where $f_{i, j}$ is the fraction of the source cell $i$ contributing to destination cell $j$ and $\mathrm{AS}_{i}$ and $\mathrm{AD}_{j}$ are the areas of the source and destination cells.

The second step is the multiplication of the emissions on the source grid by the regridding weight matrix and, if previously defined by the user in the emission inventory configuration file, the corresponding scaling and/or masking factors to produce emissions on the destination grid. Countryspecific scaling and masking factors are generated with a gridded country mask created during the initialization process. A current limitation of the masking method is that it does not consider that country border cells may include emissions of more than one country (i.e. it is assumed that all emissions belong to the country that contains the largest fraction of the cell). This limitation is mainly driven by the fact that most of the original inventories do not provide the information on the emitting country (i.e EDGAR, HTAP, ECLIPSE and CEDS report total emissions per grid cell but do not specify which fraction corresponds to which country). Future improvements will include the use of this information when given by the original inventory (i.e. EMEP and TNO_MACC-iii).

In the case of point source inventories (e.g. volcano degassing emissions) that are not reported on a regular grid but on specific lat-long locations, the remapping is performed using a nearest-destination-to-source approach. (When multiple source points are mapped into the same grid cell, the destination is the sum of the source emission values.) For point source emissions, neither scaling nor masking options are available, as the user can directly modify and/or erase individual point sources in the corresponding inventory input file.

The regridding process allows the user to remap the original emissions to global or regional grids with flexible spatial resolutions and several map projections, including regular lat-long, rotated lat-long, Lambert conformal conic and Mercator. Other map projections (e.g. polar stereographic) can potentially be added to the processing system in future releases. Figure 3 shows an example of the $0.1^{\circ} \times 0.1^{\circ}$ HTAPv2.2 BC transport emissions regridded onto (a) a $1^{\circ} \times 1.4^{\circ}$ global regular lat-long domain, (b) a $0.1^{\circ} \times 0.1^{\circ}$ regional rotated lat-long domain, (c) a $50 \mathrm{~km} \times 50 \mathrm{~km}$ regional Mercator grid and (d) a $4 \mathrm{~km} \times 4 \mathrm{~km}$ regional Lambert conformal conic grid.

In its current version, HERMESv3_GR does not use any type of spatial proxy (e.g. land use, population data) dur- ing the remapping process. The main reason for this is that most of the inventories currently available in the emission data library have a spatial resolution that is higher and suitable enough for global and regional air quality modelling (i.e. $\left.0.1^{\circ} \times 0.1^{\circ}\right)$. However, for those inventories with low spatial resolution (e.g. ECLIPSEv5a, $0.5^{\circ} \times 0.5^{\circ}$ ) the application of sector-specific spatial proxies may be of importance when performing the remapping onto finer working domains. Future work will focus on improving this limitation by rebalancing the interpolation weights derived from ESMF with weight factors based on spatial proxies.

\subsubsection{Vertical distribution}

Once the emissions are allocated to the horizontal grid, the next step is to distribute them across the vertical layers of the destination domain. For this task, two input files are required: (i) a CSV file containing a description of the domain's vertical layers (i.e. approximate heights above the ground of the top of each vertical layer, in metres) and (ii) a CSV file containing a description of the vertical profile ID previously assigned by the user in the emission inventory configuration file (i.e. fraction of emissions assigned to each vertical layer, between 0 and 1). Using this information, HERMESv3_GR interpolates the original emissions to the modelling domain layers.

Note that HERMESv3_GR is currently designed as an offline model and cannot use or take into account the variability of the vertical layer depth used by atmospheric chemistry models based on sigma vertical coordinates. Consequently, the system cannot distribute the emissions to the exact sigma levels of the models (which vary slightly in time and space) but to a set of fixed vertical levels that are close to them. This assumption is in line with previous modelling works (e.g. Mailler et al., 2013). Moreover, the impact of this limitation can be assumed to be minor when compared to the large uncertainty and variability associated with the emission vertical profiles available in the literature (e.g. Bieser et al., 2011).

Figure 4 shows a graphical example of how the vertical distribution is performed. In the example, the destination modelling domain is defined as six layers (including the surface layer) with top heights of 75, 140, 190, 500 and $1200 \mathrm{~m}$ above ground level (ma.g.1.). On the other hand, the proposed vertical profile ID (V001) indicates that $0 \%$ of the total emissions should be assigned between 0 and $100 \mathrm{~m}$ a.g.l., $10 \%$ between 100 and $200 \mathrm{~m}$ a.g.l., and the remaining $90 \%$ between 200 and $1000 \mathrm{~m}$ a.g.l. Note that the number and description of the vertical layers used to define the vertical profiles do not have to match the ones of the destination domain. HERMESv3_GR internally interpolates homogenously the original weight fractions to the modelling domain's layers taking into account the thickness of each layer.

The user is able to define and assign any vertical profile to any emission inventory, pollutant sector or pollutant species. Some suggested vertical profiles for the energy and manu- 
(a)

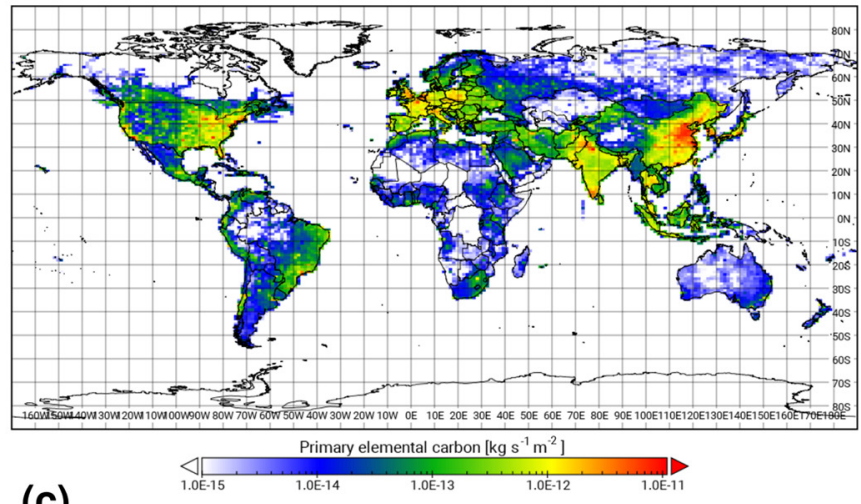

(c)

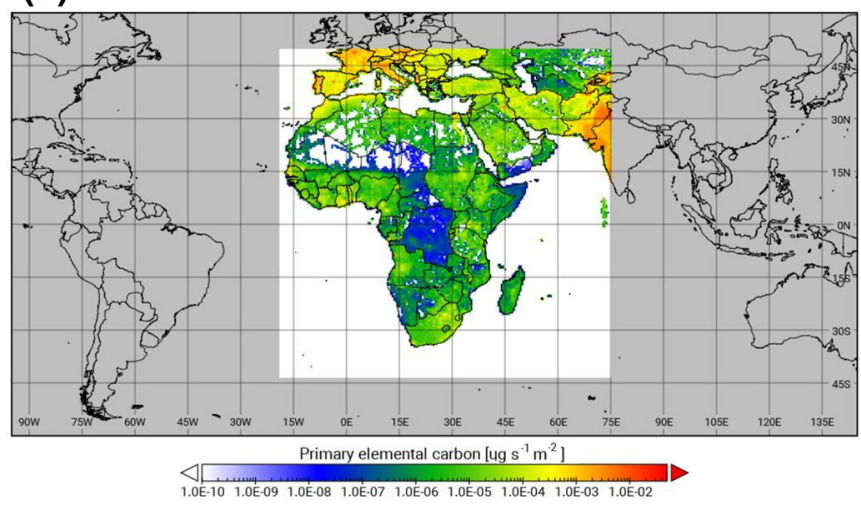

(b)

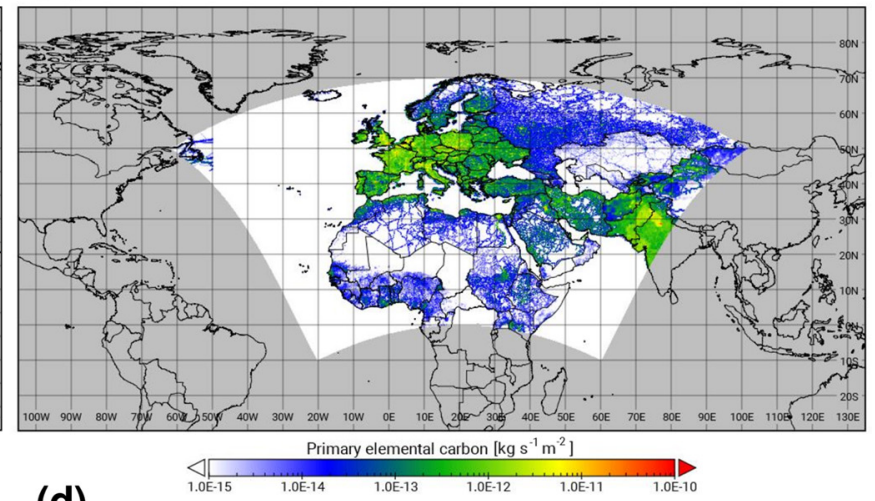

(d)

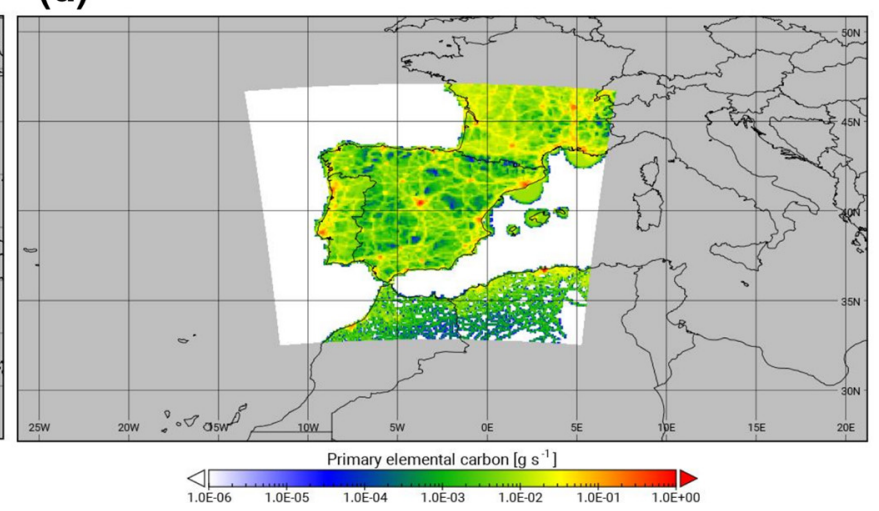

Figure 3. Examples of the HTAPv2.2 black carbon transport emissions regridded onto a $1^{\circ} \times 1.4^{\circ}$ global regular lat-long domain (a), $0.1^{\circ} \times 0.1^{\circ}$ rotated lat-long domain (b), $50 \mathrm{~km} \times 50 \mathrm{~km}$ Mercator grid (c) and $4 \mathrm{~km} \times 4 \mathrm{~km}$ Lambert conformal conic grid (d). All maps are displayed in an equirectangular projection.

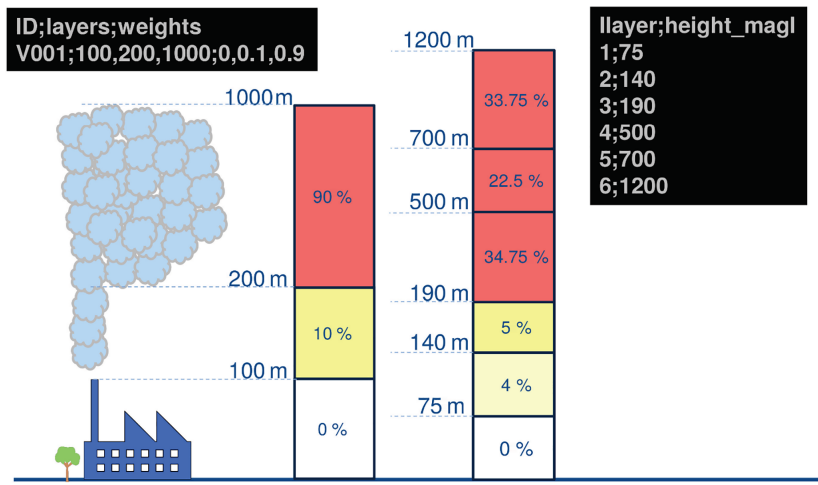

Figure 4. Schematic representation of the emission vertical distribution process implemented within HERMESv3_GR. Left side shows an example of a vertical profile description ("V001"), which allocates $10 \%$ of emissions between 100 and $200 \mathrm{~m}$ a.g.l. and the remaining $90 \%$ between 200 and $1000 \mathrm{~m}$ a.g.l. Right side shows an example of the vertical description of the domain. Original vertical weights are interpolated to the model vertical layers according to their thickness. facturing industry (Bieser et al., 2011) and the air traffic sectors (Olsen et al., 2013) are included in the HERMESv3_GR database.

For the GFASv1.2 biomass burning inventory, the vertical emission distribution is not performed with a fixed vertical profile but using two parameters that define (i) the maximum altitude of the fire plume injection height ("method") and (ii) how the emissions are distributed across the layers below this maximum height ("approach"). The fire plume injection height is directly provided by GFASv1.2 following two different methods. The first method ("sofiev") is based on a semi-empirical parameterization detailed in Sofiev et al. (2013). The second method ("prm") consist of a plume rise model described by Paugam et al. (2015). Regarding the approach, users can also choose between two options. The first one ("uniform"), consist of distributing uniformly all the emissions across the layers below the maximum injection height. The second one ("50_top") indicates that $50 \%$ of all emissions are allocated to the vertical layer that intersects with the maximum injection height, and the other $50 \%$ are distributed uniformly across the layers below the maximum injection height. The two approaches are derived from the work by Veira et al. (2015), in which a sensitivity analy- 
sis is performed to see the impact of the vertical distribution of forest fire emissions on black carbon concentrations. Although uniform vertical distributions are used in most modelling studies, some work has also shown that fires with high injection heights might emit a large fraction of the emissions into the upper part of the plumes (e.g. Luderer et al., 2006).

Similarly, in the case of point source emission inventories (e.g. volcano degassing), the vertical distribution is not defined using a fixed vertical profile but with the injection height field included in the input inventory file, which can be adjusted individually for each point source. Emissions are distributed homogenously across all the layers below the defined injection height.

\subsubsection{Temporal distribution}

This process temporally distributes the emissions from their original resolution (e.g. annual) to the one defined by the user (monthly, daily or hourly). The emissions are multiplied by the user-defined monthly, weekly and hourly weight factors, which are specified in separated CSV files with the corresponding profile ID (i.e. "MXXX", "DXXX" and "HXXX" for monthly, weekly and hourly profiles, "XXX" being a three-digit numeric code that starts at "001"). Alternatively, users can also provide the temporal profiles using gridded files, which contain specific weight factors for each grid cell.

As in the case of the vertical profiles, the user is left free to define and assign any temporal profile to each pollutant sector and species. The HERMESv3_GR database includes by default the monthly, daily and hourly temporal profiles reported by LOTOS-EUROS (Denier van der Gon et al., 2011), which are partially based on the GENEMIS project (Friedrich and Reiss, 2004) and Hodzic et al. (2012).

HERMESv3_GR estimates emissions in coordinated universal time (UTC). However, all the user-defined hourly temporal profiles need to be introduced in local standard time (LST). For each cell of the destination grid and time step, HERMESv3_GR converts the UTC simulation date to the corresponding LST and assigns to it the adequate local temporal factor. This conversion is done using as a basis a time zone grid created during the initialization process. Having the time zone information on each cell allows HERMESv3_GR to take into account daylight saving time (DST) changes, which do not necessarily occur on the same date every year and in every country.

Figure 5 shows an example of the 6-hourly evolution (00:00, 06:00, 12:00 and 18:00 UTC) of the ECLIPSEv5a $\mathrm{NO}_{x}$ transport emissions for a $24 \mathrm{~h}$ simulation performed on a $0.5^{\circ} \times 0.7^{\circ}$ global grid for the 23 February 2015 . It is observed how the diurnal variation of emissions in different cities is in line with their local time. For instance, at 00:00 UTC time (first time step of the simulation), emissions in China are at their morning peak (08:00 LST), whereas in Barcelona they are at their minimum (01:00 LST) and in New York close to their afternoon peak (19:00 LST).
The application of gridded profiles can be of importance for those emission sectors whose temporal variation is not uniform across space due to local influences such as climatology conditions (e.g. the effect of temperature on residential combustion emissions) or socio-demographic patterns (e.g. the effect of farming practices on agricultural emissions). Figure 6 compares the monthly agricultural soil $\mathrm{NH}_{3}$ emissions (March and June 2010) reported by EDGARv4.3.2 in east Asia when using its default temporal profile (Fig. 6a and c) and when combined with updated gridded temporal weights that consider the effect of meteorology and crop calendars (Fig. $6 \mathrm{~b}$ and d). These gridded profiles were derived from the monthly inventories reported by Zhang et al. (2018) for China and Paulot et al. (2014) for rest of the world, the seasonality of which is based on the temporal parameterizations reported by Skjøth et al. (2011).

Results show large differences between the two results, especially in China and India, the main emitter countries for this sector. According to Fig. 6e, in China the default profile allocates most of the emissions in March, whereas the updated temporal profile gives more weight to the months of June and July. Similarly, the default profile presents a flat distribution over India, whereas the improved profile indicates a peak during the months of May and June (Fig. 6f). In both cases, the updated monthly distribution is more in line with the seasonality of the $\mathrm{NH}_{3}$ volume mixing ratio derived from the NASA's Atmospheric Infrared Sounder (AIRS) instrument (Warner et al., 2017). The possibility offered by HERMESv3_GR to use gridded temporal profiles derived from meteorological parameterizations can be extended to other sources such as the residential combustion sector, for which the application of the heating degree day approach has been proved to be effective (e.g. Mues et al., 2014).

\subsubsection{Speciation mapping}

This process converts the pollutants provided in the original emission inventories to the species needed by the atmospheric chemistry model of interest and its corresponding gas-phase and aerosol chemical mechanism. The conversion is performed using a speciation CSV file, in which the user defines mapping expressions between the source inventory pollutants and destination chemical species. Each mapping expression defines the pollutant-to-species relationships and factors for converting the input emissions pollutant to the desired model species.

These conversion factors are mass-based (i.e. gram of chemical species per gram of source pollutant) for all source inventory pollutants except for NMVOC, which requires a specific approach (see paragraph below). The factors proposed for $\mathrm{NO}_{x}$ assume a split of 0.9 for $\mathrm{NO}$ and 0.1 for $\mathrm{NO}_{2}$ for all sectors (Houyoux et al., 2000) except for road transport and biomass burning, for which specific factors are derived from the works by Burling et al. (2010) and Rappenglueck et al. (2013). In the case of $\mathrm{PM}_{2.5}$, the factors 

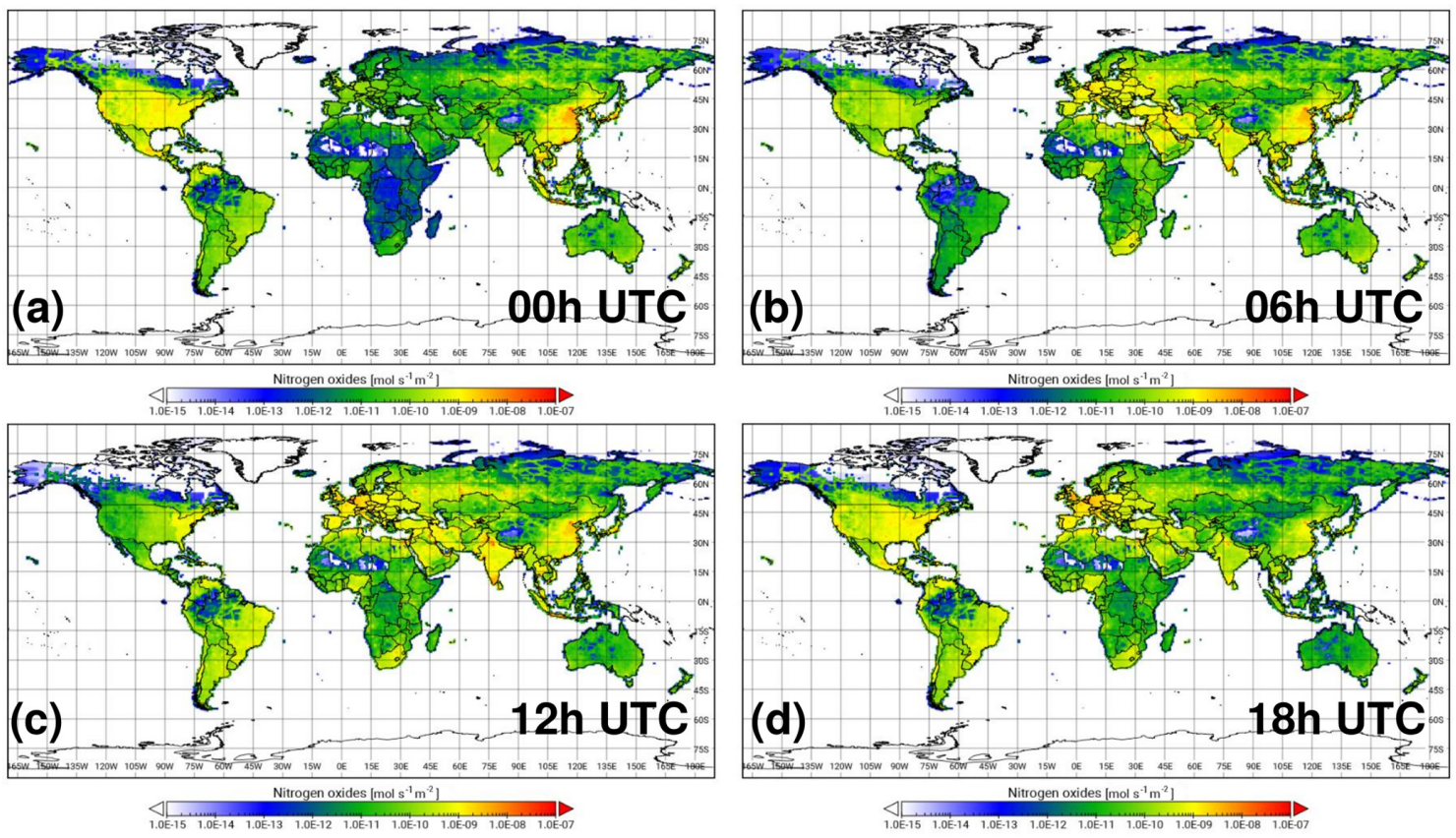

(e)

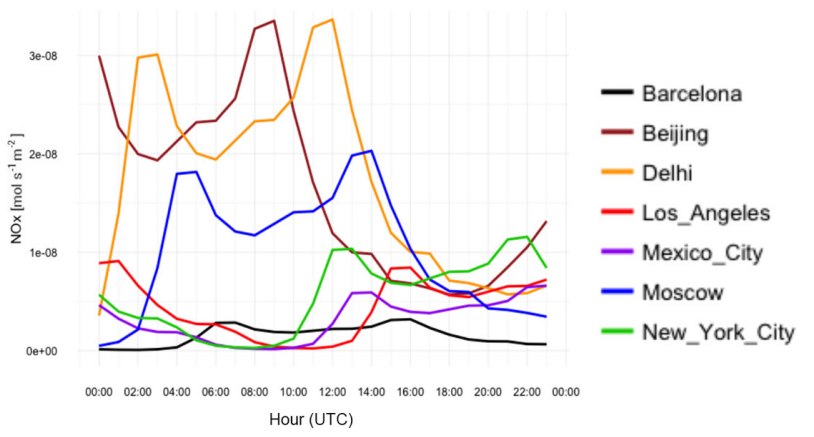

Figure 5. Global hourly $\mathrm{NO}_{x}$ transport emissions $\left(\mathrm{mol} \mathrm{s}^{-1} \mathrm{~m}^{-2}\right.$ ) derived from ECLIPSEv5a at 00:00 (a), 06:00 (b), 12:00 (c) and 18:00 (d) UTC and the diurnal evolution estimated in the grid cells where different global cities are located (e).

are derived from multiple sources of information including the particular matter SPECIATE (Simon et al., 2010) and SPECIEUROPE (Pernigotti et al., 2016) databases and the works by Visschedijk et al. (2007) and Reff et al. (2009). Source-specific organic matter (OM) to OC fractions are derived from Klimont et al. (2017). For pollutants that have only one way of being speciated (e.g. mapping the $\mathrm{CO}$ pollutant to the $\mathrm{CO}$ species) a default factor of 1 is proposed for all sources and inventories. During the chemical speciation process, HERMESv3_GR also performs a conversion from mass to moles for the gas-phase species using a molecular weight CSV file included in the input database of the system. Note that for $\mathrm{NO}_{x}$ two molecular weights are proposed since some inventories report emissions as NO ("nox_no", $30 \mathrm{~g} \mathrm{~mol}^{-1}$ ) and some as $\mathrm{NO}_{2}$ ("nox_no2", $46 \mathrm{~g} \mathrm{~mol}^{-1}$ ).

For NMVOC emissions reported as individual chemical compounds (e.g. $\mathrm{C}_{2} \mathrm{H}_{4} \mathrm{O}$ in GFASv1.2) or following the GEIA 25 NMVOC groups (e.g. voc15 in
EDGARv4.3.2_VOC), the proposed conversion factors are mole-based (i.e. mol of chemical species per mol of source pollutant) and are derived from the mechanism-dependent mapping tables developed by Carter (2015). In this case, the conversion from mass to moles of original emissions is performed beforehand and also using the information on the molecular weight CSV file.

Finally, for NMVOC emissions reported as a single category (i.e. as a sum of $n$ individual chemical compounds) (e.g. EMEP), the conversion factors proposed in HERMESv3_GR for each inventory $i$, pollutant sector $s$ and chemical species $\bar{e}\left(\mathrm{SF}_{\bar{e}, s, i}\right)$ were estimated as follows (Eq. 5): 

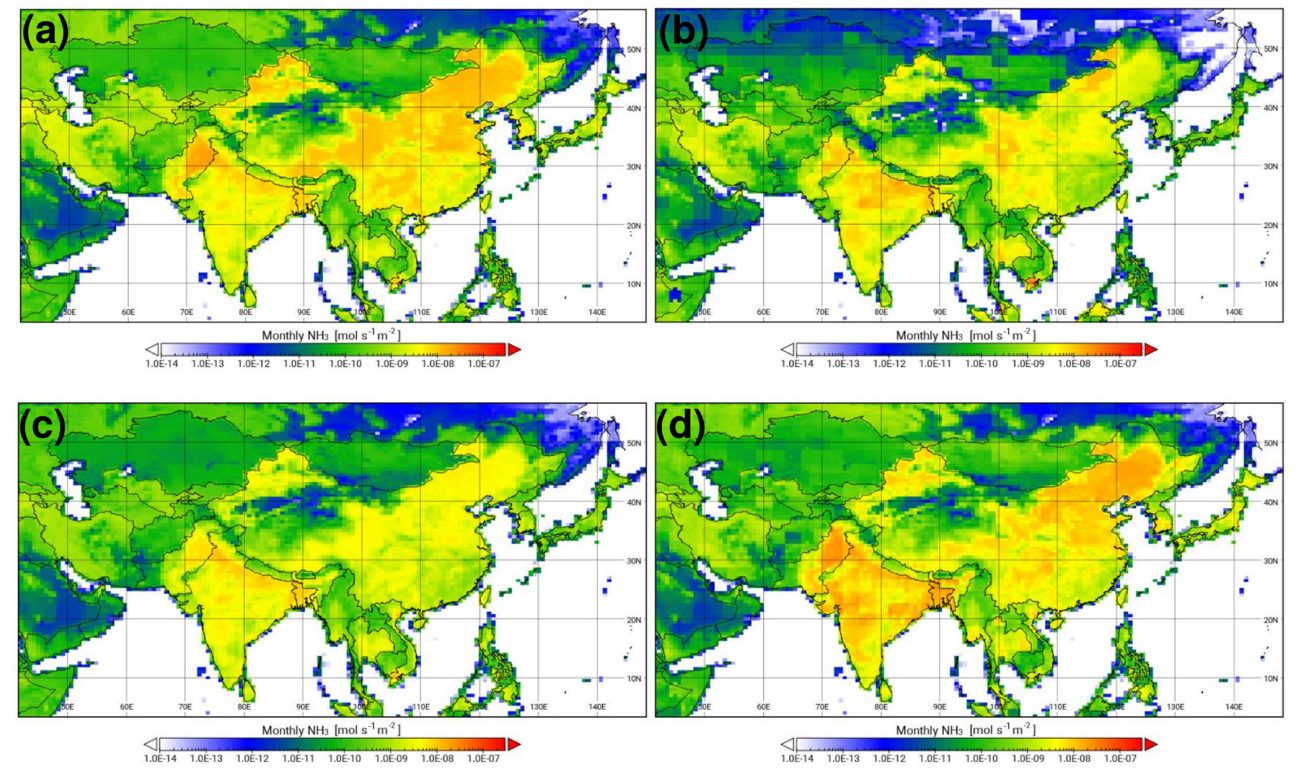

(e)

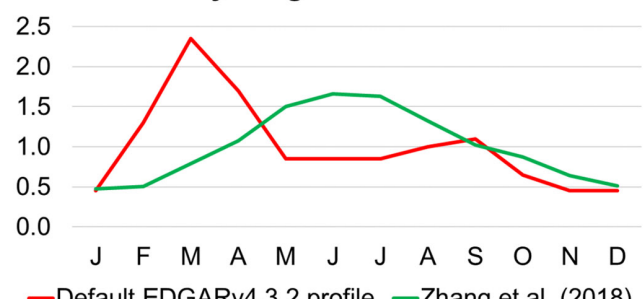

(f)

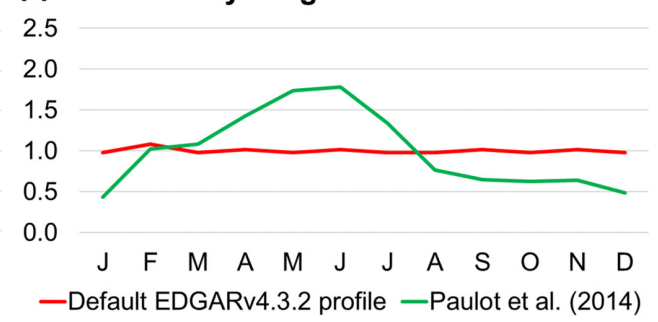

Figure 6. Monthly NH3 agricultural soil emissions $\left(\mathrm{mol} \mathrm{s}^{-1} \mathrm{~m}^{-2}\right)$ estimated with HERMESv3_GR in east Asia $\left(0.5^{\circ} \times 0.7^{\circ}\right)$ for March and June using the default temporal profiles reported by EDGARv4.3.2 (a, c) and a gridded temporal profile derived from the works of Paulot et al. (2014) and Zhang et al. (2018) (b, d), and monthly weight factors obtained in China and India for each case (e, f).

$\mathrm{SF}_{\bar{e}, s, i}=\sum_{j=1}^{n} \frac{X_{j, s}}{\mathrm{MW}_{j}} \cdot C_{j, \bar{e}}$

where $X_{j, s}$ is the mass fraction of chemical compound $j$ to total NMVOC emissions for source $s, \mathrm{MW}_{j}$ is the molecular weight of chemical compound $j$ and $C_{j, i}$ is the molebased conversion factor of chemical compound $j$ to destination chemical species $\bar{e} . X_{j, s}$ values are obtained from the NMVOC SPECIATE database, while $M W_{j}$ and $C_{j, i}$ were obtained from Carter (2015). The unit of resulting proposed conversion factors is mol of chemical species per gram of source pollutant.

Each line of the speciation CSV file corresponds to a specific profile, which is cross-referenced with the profile ID previously defined in the emission inventory configuration file (i.e "EXXX", "XXX" being a three-digit numeric code that starts at "001"). The columns of the file refer to the names of the destinations species, which need to match the atmospheric chemistry model registry names of the emission variables. The HERMESv3_GR database currently in- cludes speciation profiles for the Carbon Bond 05 (CB05, CB05e51) (Whitten et al., 2010) and the Regional Acid Deposition Model second-generation (RADM2) (Stockwell et al., 1990) gas-phase mechanisms, as well as the fifthand sixth-generation aerosol modules (AERO5, AERO6) (Roselle et al., 2008; Appel et al., 2017) and the Modal Aerosol Dynamics Model for Europe with the Secondary Organic Aerosol Model (MADE-SORGAM) aerosol mechanisms (Ackermann et al., 1998; Schell et al., 2001). As in the case of the temporal and vertical weight factors, the user can create their own speciation profiles using other sources of information.

As an illustration, Table 2 shows two examples of proposed speciation profiles and corresponding mapping expressions included in the HERMESv3_GR database. The first one maps the original GFASv1.2 emission species to the CB05 gas-phase and AERO5 aerosol chemical mechanisms. As shown, original $\mathrm{NO}_{x}$ (which is expressed as $\mathrm{NO}$ ) is mapped to the $\mathrm{CB} 05$ species nitrogen monoxide (NO), nitrogen dioxide $\left(\mathrm{NO}_{2}\right)$ and nitrous acid (HONO) using mass-based conversion factors of 0.72 ("nox_no*0.72"), 
Table 2. Example of speciation profiles included in HERMESv3_GR for mapping the GFASv1.2 emissions to CB05 and AERO5 and the CEDS road transport emissions to RADM2 and MADE/SOGARM chemical mechanisms. Any species not mentioned in this table are defined in Table A2 in the Appendix.

\begin{tabular}{|c|c|c|c|}
\hline \multicolumn{2}{|r|}{ GFASv1.2 CB05 + AERO5 speciation profile } & \multicolumn{2}{|r|}{$\begin{array}{c}\text { CEDS road transport RADM2 } \\
+ \text { MADE-SORGAM speciation profile }\end{array}$} \\
\hline Species & Expression & Species & Expression \\
\hline NO & $0.72 *$ nox_no ${ }^{\mathrm{a}}$ & NO & $0.84 *$ nox_no $2^{b}$ \\
\hline $\mathrm{NO} 2$ & $0.18^{*}$ nox_no ${ }^{\mathrm{a}}$ & $\mathrm{NO} 2$ & $0.16^{*}$ nox_no $2^{\mathrm{b}}$ \\
\hline HONO & $0.1 *$ nox_no ${ }^{\mathrm{a}}$ & $\mathrm{CO}$ & co \\
\hline $\mathrm{CO}$ & co & $\mathrm{SO} 2$ & so2 \\
\hline $\mathrm{SO} 2$ & so2 & NH3 & nh3 \\
\hline NH3 & nh3 & ALD & $\operatorname{voc} 22$ \\
\hline ALD2 & $\mathrm{c} 2 \mathrm{~h} 4 \mathrm{o}$ & ETH & voc02 \\
\hline ALDX & 0 & $\mathrm{HC} 3$ & $0.95 * \operatorname{voc} 01+\operatorname{voc} 03+\operatorname{voc} 04+0.4 * \operatorname{voc} 09+0.69 * \operatorname{voc} 18+\operatorname{voc} 20$ \\
\hline BENZENE & c6h6 & HC5 & $0.05 * \operatorname{voc} 01+\operatorname{voc} 05+0.43 * \operatorname{voc} 06+0.31 * \operatorname{voc} 18$ \\
\hline ETH & $\mathrm{c} 2 \mathrm{~h} 4$ & $\mathrm{HC} 8$ & $0.57 * \operatorname{voc} 06+\operatorname{voc} 17+\operatorname{voc} 19$ \\
\hline ETHA & $\mathrm{c} 2 \mathrm{~h} 6$ & $\mathrm{HCHO}$ & $\operatorname{voc} 21$ \\
\hline ETOH & c2h5oh & ISO & $\operatorname{voc} 10$ \\
\hline FORM & 0 & KET & $\operatorname{voc} 23$ \\
\hline IOLE & $0.5 *$ high alkenes & OL2 & $\operatorname{voc} 07$ \\
\hline ISOP & $\mathrm{c} 5 \mathrm{~h} 8$ & OLI & $\operatorname{voc} 11+\operatorname{voc} 12$ \\
\hline MEOH & $\operatorname{ch} 3 \mathrm{oh}$ & OLT & $\operatorname{voc} 08$ \\
\hline OLE & $\mathrm{c} 8 \mathrm{~h} 16+\mathrm{c} 5 \mathrm{~h} 10+\mathrm{c} 3 \mathrm{~h} 6+\mathrm{c} 4 \mathrm{~h} 8+\mathrm{c} 6 \mathrm{~h} 12+0.5 *$ high alkanes & ORA1 & $0.44 * \operatorname{voc} 24$ \\
\hline \multirow[t]{3}{*}{ PAR } & $4 * \mathrm{c} 4 \mathrm{~h} 10+6 * \mathrm{c} 6 \mathrm{~h} 14+5 *$ high alkanes $+6 * \mathrm{c} 8 \mathrm{~h} 16+3 * \mathrm{c} 5 \mathrm{~h} 10$ & ORA2 & $0.56^{*} \operatorname{voc} 24$ \\
\hline & $+\mathrm{c} 3 \mathrm{~h} 6+3 * \mathrm{c} 3 \mathrm{~h} 6 \mathrm{o}+2 * \mathrm{c} 4 \mathrm{~h} 8+7 * \mathrm{c} 7 \mathrm{~h} 16+4 * \mathrm{c} 6 \mathrm{~h} 12$ & TOL & $0.293 *$ voc13+voc14 \\
\hline & + high alkenes $+5 * \mathrm{c} 5 \mathrm{~h} 12+1.5 * \mathrm{c} 3 \mathrm{~h} 8$ & XYL & voc16+voc17 \\
\hline SESQ & 0 & PM_10 & 0 \\
\hline TERP & terpenes & PM25J & 0 \\
\hline TOL & $\operatorname{ch} 2 \mathrm{o}+\mathrm{c} 7 \mathrm{~h} 8$ & PM25I & 0 \\
\hline XYL & $\mathrm{c} 8 \mathrm{~h} 10$ & ECJ & $\mathrm{bc}^{*} 0.8$ \\
\hline DMS & c2h6s & ECI & $\mathrm{bc} * 0.2$ \\
\hline HCL & 0 & ORGJ & oc* 0.8 \\
\hline POA & $1.8 * \mathrm{oc}$ & ORGI & $\mathrm{oc}^{*} 0.2$ \\
\hline PEC & bc & NO3J & 0 \\
\hline PNO3 & 0 & NO3I & 0 \\
\hline PSO4 & 0 & SO4J & 0 \\
\hline PMFINE & pm25-oc-bc & SO4I & 0 \\
\hline PMC & 0 & & \\
\hline SULF & 0 & & \\
\hline
\end{tabular}

${ }^{\mathrm{a}}$ GFASv1.2 $\mathrm{NO}_{x}$ emissions are reported as $\mathrm{NO}{ }^{\mathrm{b}}$ CEDS NO${ }_{x}$ emissions are reported as $\mathrm{NO}_{2}$.

0.18 ("nox_no*0.18”) and 0.1 (“nox_no*0.1") (Burling et al., 2010). The terminal olefin bond (OLE) CB05 species is composed of the following GFASv1.2 NMVOCs: $\mathrm{C}_{8} \mathrm{H}_{16}$, $\mathrm{C}_{5} \mathrm{H}_{10}, \mathrm{C}_{3} \mathrm{H}_{6}, \mathrm{C}_{4} \mathrm{H}_{8}, \mathrm{C}_{6} \mathrm{H}_{12}$ and $50 \%$ of other high alkanes ("c8h16+c5h10+c3h6+c4h8+c6h12+0.5*high alkanes"). On the other hand, the difference between total primary $\mathrm{PM}_{2.5}$ and carbonaceous species (OC and $\mathrm{BC}$ ) is mapped to the other fine aerosols (PMFINE) AERO5 species ("pm2.5-oc-bc"). In the second example, the CEDS road transport emissions are mapped to the RADM2 gas-phase mechanism and the MADE-SORGAM aerosol module. $\mathrm{NO}_{x}$ emissions (which are originally reported as $\mathrm{NO}_{2}$ ) are mapped to $\mathrm{NO}$ and $\mathrm{NO}_{2}$ using massbased conversion factors of 0.84 ("nox_no $2 * 0.84$ ") and 0.16 ("nox_no2*0.16") (Rappenglueck et al., 2013). The toluene (TOL) RADM2 species is estimated to be the sum of the voc14 (toluene) and $29.3 \%$ of the voc13 (benzene) GEIA groups ("0.293*voc13+voc14") (Carter, 2015). Total BC emissions are assumed to be $20 \%$ in nucleation mode (ECI, "bc*0.2") and $80 \%$ in accumulation mode (ECJ, "bc*0.8") (Tuccella et al., 2012). As shown in these examples, the mapping expressions can combine different types of mathematical expressions (i.e. addition, subtraction, multiplication).

\subsubsection{Writing module}

The calculated emissions are written in NetCDF4 uncompressed files following the conventions of the selected atmospheric chemistry model. During this process, the following actions take place: (i) conversion of units and (ii) inclusion of mandatory global attributes. 


\subsection{Technical implementation}

HERMESv3_GR is coded using Python 2.7.X and requires numpy $(>=1.9 .1)$, NetCDF4 $(>=1.3 .1)$, cdo $(>=1.3 .3)$, pandas $(>=0.22 .0)$, geopandas $(>=0.4 .0)$, pyproj $(>=1.9 .5 .1)$, configargparse $(>=0.11 .0)$, cf_units $(>=1.1 .3)$, ESMPy $(>=7.1 .0)$, holidays $(>=0.4 .1)$, pytz $(>=2017.2)$, timezonefinder $(>=2.1 .0)$, mpi4py $(>=3.0 .0)$ and pytest $(>=3.6 .1)$ Python libraries.

The emission core module of HERMESv3_GR is parallelized using a domain decomposition strategy. This approach is considered to be the most effective since emissions are computed independently for each destination grid cell and no communication between cells is needed during the calculation process (see Eq. 1). Moreover, applying domain decomposition also allows decreasing the memory consumption per computational node.

Figure 7 shows a schematic representation of the domain decomposition strategy applied in HERMESv3_GR. During the spatial regridding, the destination working domain is divided into vertical sections, maintaining each column as indivisible. The number of divisions is equal to the number of processors to be used ( $\left.P_{-} 0, P_{-} 1, \ldots\right)$, which is defined by the user. The emission regridding process is performed independently in each processor and for each vertical section. The maximum number of cores to be used is equal to half of the number of columns of the destination domain. This limitation is defined by the ESMF software, which needs, at least, two complete columns to perform the spatial regridding. The 2-D regridded emissions are kept in memory until the writing operation. During this task, the vertical (v0, v1, $\ldots)$ and temporal $(\mathrm{t} 0, \mathrm{t} 1, \ldots)$ weight factors previously estimated in the vertical and temporal distribution functions are applied to each emission subdomain in order to transform the 2-D arrays (longitude, latitude) into 4-D arrays (time, vertical layer, longitude, latitude). This strategy allows reducing the time during which the memory consumption is higher. Finally, each worker process simultaneously writes its result to a common NetCDF4 file, which ensures the gathering of the different subsets of the working domain into a single output. Alternatively, the user can select the option of executing the writing function in serial mode (i.e. using only one processor).

A scalability test was performed using the supercomputer MareNostrum 4, which is hosted by the BSC, in order to determine the capability of HERMESv3_GR to scale up the emission calculation process. MareNostrum 4 is a supercomputer based on Intel Xeon Platinum processors at $2.1 \mathrm{GHz}$ from the Skylake generation. It is a Lenovo system composed of SD530 compute racks, an Intel Omni-Path highperformance network interconnect and running SuSE Linux Enterprise Server as an operating system. It consists of 48 racks housing 3456 nodes, each one equipped with 48 cores and $96 \mathrm{~Gb}$ of memory ( $2 \mathrm{~Gb}$ per core) (https://www.bsc.es/ marenostrum/marenostrum, last access: May 2019). HER-
MESv3_GR was executed using a number of cores from 1 to 510, doubling the number in each successive test until using all cores of a node (i.e. 1, 2, 4, 8, ., 48) and then adding 48 (a whole node) until 510 (i.e. 96, 144, .., 510). Two separate sets of tests were performed: one using the parallel writing function and another using the serial approach.

All the tests were performed using a rotated lat-long destination grid of $0.1^{\circ} \times 0.1^{\circ}$ with 701 rows, 1021 columns and 48 vertical layers covering North Africa, Europe and the Middle East (Fig. 3b). Hourly CB05 and AERO5 speciated emissions were estimated for 24 time steps using as input all the available emission pollutants and sectors of the TNO_MACC_III (Europe) and HTAPv2.2 (remaining countries) inventories.

As shown in the stacked area chart of Fig. 7, the increased number of cores used in the simulations speeds up the computations. The total execution time decreases from $4842.6 \mathrm{~s}$ ( 1 core) to $1247 \mathrm{~s}$ ( 510 cores), the lowest value being observed when using 32 cores $(800.7 \mathrm{~s})$. The most time-demanding function changes according to the number of cores used. For 1 to 8 cores, most of the computational work is done during the spatial regridding (between $54 \%$ and $34 \%$ ) and the temporal distribution (between $39 \%$ and $25 \%$ ), whereas for the other cases ( 16 to 510 cores), the writing process increasingly becomes the main time consumer (up to $84 \%$ of the total time when using 510 cores). These results clearly indicate that the parallel writing function does not scale properly. The reason behind this behaviour comes from the fact that the NetCDF4 Python library writes the results in row-major order (C style), while during the spatial regridding ESMF divides the domain into vertical sections (column-major order; FORTRAN style). For each vertical division, NetCDF4 Python has to call the writing function as many times as the number of rows that conform to the domain. Subsequently, an increase in cores (i.e. an increase in vertical divisions) directly increases the execution time of the parallel writing process. The performance of the system when applying the serial writing approach (black line with markers) varies as a function of the processors used. For a low number of cores (i.e. 1 to 48), parallel writing is faster than serial writing. Nevertheless, when using 96 processors or more, serial writing becomes faster since its execution time remains almost constant, in contrast to what is experienced with the parallel approach. This fact allows reducing the total execution time by a factor of up to 1.5 when using 510 cores. The potential disadvantage of using serial writing is that for large emission experiments (i.e. large domains) the user may run into memory problems since all the data need to be treated by a single processor. In the present test, we solved this issue by using all the memory resources of a compute node without sharing them with other users (i.e. $96 \mathrm{~Gb}$ ). Considering the advantages and disadvantages of each method, both the serial and parallel writing approaches are enabled in HERMESv3_GR. 


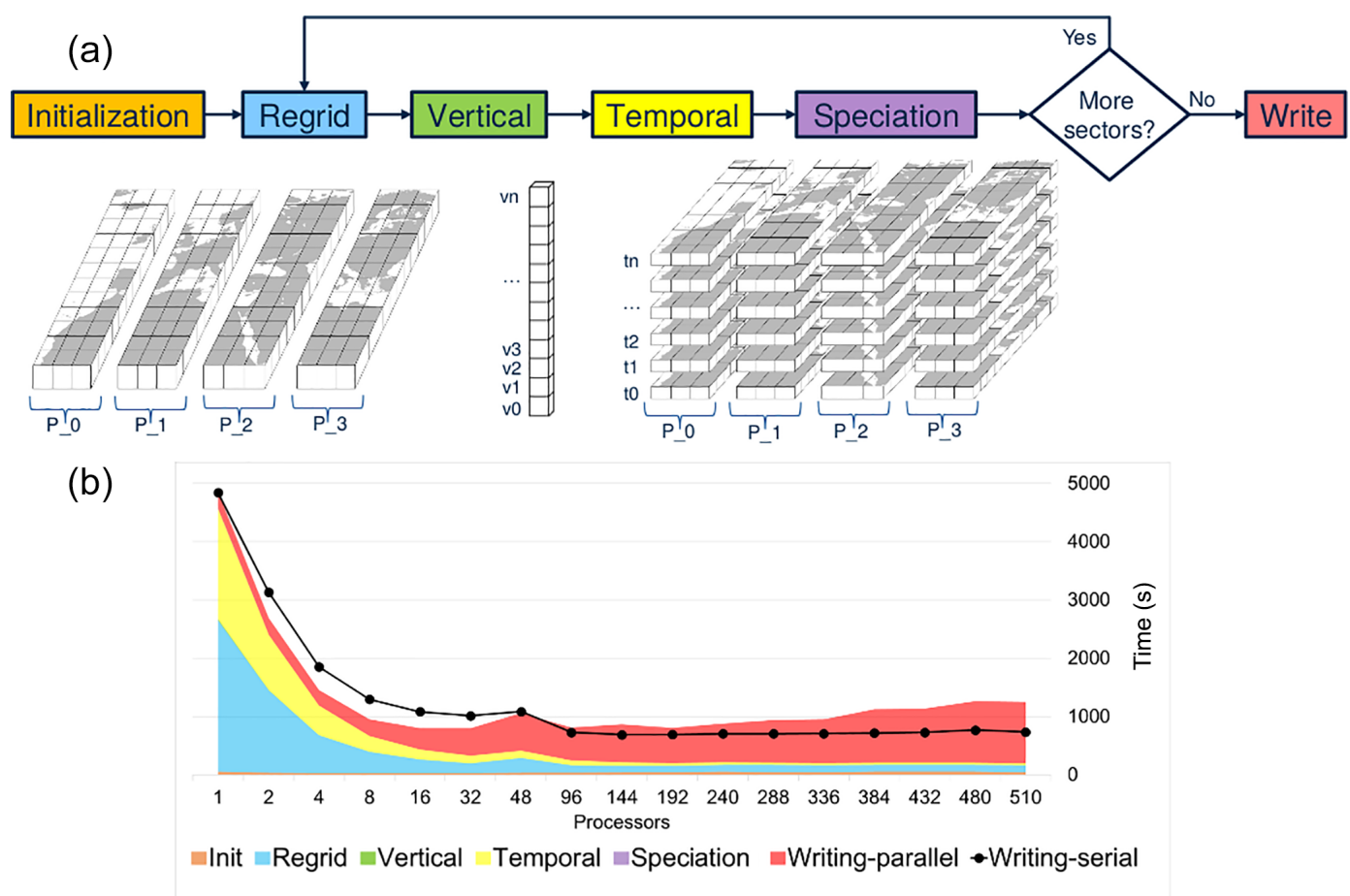

Figure 7. Schematic representation of the parallelization of the emission core module of HERMESv3_GR (a) and computational times obtained for each functionality (regrid, vertical, temporal, speciation, and parallel writing or serial writing) for the scalability test performed (b). The destination working domain is divided into vertical sections, according to the number of processors to be used $\left(P_{-} \_, P_{-} 1, \ldots\right)$. Vertical $(\mathrm{v} 0, \mathrm{v} 1, \ldots)$ and temporal $(\mathrm{t} 0, \mathrm{t} 1, \ldots)$ weight factors are applied to each section in order to transform the 2-D arrays (longitude, latitude) into 4-D arrays (time, vertical layer, longitude, latitude).

The low performance of the parallel writing function will be addressed in future versions of HERMESv3_GR. For this, two strategies will be tested, including (i) the integration of an I/O (input-output) server that allows writing completed rows in row-major order and (ii) the use of other libraries specific for parallel writing (e.g. pnetcdf). Despite this shortcoming, the current parallelization strategy allows HERMESv3_GR execution time to be minimized to less than 15 min per run (32 cores), which can be considered acceptable in an operational environment.

\section{Implementations}

HERMESv3_GR has been successfully tested in different atmospheric chemistry models. The system is currently implemented within the NMMB-MONARCH, which contributes to the multi-model ensemble forecasts of the International Cooperative for Aerosol Prediction (ICAP) (http://icap. atmos.und.edu/, last access: May 2019). HERMESv3_GR has also been coupled with the CMAQ in the framework of the AIRE-CDMX air quality forecasting system for Mexico City (http://www.aire.cdmx.gob.mx/pronostico-aire/, last access: May 2019). In the first case, HERMESv3_GR is used to provide global primary aerosol emissions to NMMB-
MONARCH, whereas in the AIRE-CDMX it is used to process the biomass burning emissions reported by GFASv1.2. Besides the two aforementioned implementations, HERMESv3_GR has been also used to perform simulations with the CALIOPE air quality forecasting system, which is based on CMAQ (http://www.bsc.es/caliope/en/forecasts? language $=e n$, last access: May 2019) and in several tests using the WRF-Chem model.

\section{Conclusions}

This paper presents HERMESv3_GR, a stand-alone multiscale emission processing system that estimates gas and aerosol emissions for use in atmospheric chemistry models. HERMESv3_GR is designed to combine and process existing inventories for the generation of emission input files for global and regional air quality modelling. During the execution, emissions from different inventories, sources and species are combined and regridded to the destination domain and are vertically and temporally disaggregated, speciated and converted to the required format of the atmospheric chemistry model of interest. HERMESv3_GR is driven by configuration files that provide a flexible and transparent 
platform for the design and implementation of intercomparison and sensitivity modelling experiments.

HERMESv3_GR represents an effort to homogenize the currently available information on emission inventories and to process them in a transparent and flexible way to produce emission outputs that can be used directly by multiple atmospheric chemistry models.

There are several features that makes HERMESv3_GR an unique emission processing system, including the following.

- User-defined grid and choice between different map projections: emissions can be computed on any global or regional domain with a regular lat-long, rotated latlong, Mercator or Lambert conformal conic projection.

- Choice between different emission inventories: the emission data library of HERMESv3_GR includes current state-of-the-art global and regional inventories that cover different sources (anthropogenic, biomass burning, volcanoes), pollutants (ozone precursor gases, acidifying gases and primary particulates) and base years (past, present and future). Moreover, country-specific scaling and masking factors defined by the user can be applied to the base inventories in order to combine and adjust them.

- Choice between different vertical, temporal and speciation profiles: HERMESv3_GR includes a dataset of profiles reported by the literature, but it also allows the user to add its own weighting factors for any pollutant sector and species. Additionally, the processing system is able to combine base inventories with gridded temporal profiles, which can be of importance for those source sectors whose temporal variation is not uniform across space (e.g. residential combustion emissions driven by temperature).

- Choice between different atmospheric chemistry models: the generated emission files can be used as input for the CMAQ, WRF-CHEM and NMMB-MONARCH chemical transport models.

- Choice between different chemical mechanisms: base pollutants can be mapped to several gas-phase and aerosol chemical mechanism, including CB05, CB05e51, RADM2, AERO5, AERO6 and MADESORGAM. All these mechanisms are widely used in the air quality modelling community.

- Parallel implementation: the emission core module of HERMESv3_GR is parallelized using a domain decomposition strategy, which allows decreasing the execution time and memory consumption of the model. This feature can be of importance when using the processing system in operational air quality forecasting systems, for which the simulations need to be completed within the required time constraints.
Several emission outputs obtained with HERMESv3_GR are provided in this paper to illustrate its potential. The software is implemented within NMMB-MONARCH and CMAQ in the framework of the ICAP multi-model ensemble and the AIRE-CDMX air quality forecasting system for Mexico City, respectively.

It is worth noting that despite providing a flexible and simplified framework for the processing of emissions, users should have a clear knowledge of the original inventories when using HERMESv3_GR. Combining parts from different inventories could lead to substantial errors (e.g. double counting) because the definition of what is included or excluded in certain sectors and/or inventories can differ significantly (e.g. agricultural waste burning emissions are sometimes included under the agriculture source sector and sometimes excluded). It is therefore recommended that users carefully check the original descriptions of each inventory before using them. With the aim of facilitating this task, the HERMESv3_GR wiki (see Sect. 5) includes a section with a general description of each inventory and links to the official references.

Future work will consider the expansion of the emission data library to include regional inventories of regions such as Asia or America, emission datasets that are currently being developed in the framework of the Copernicus Atmosphere Monitoring Service (CAMS), as well as datasets that report emissions of greenhouse gases, so that HERMESv3_GR can also serve as input for climate modelling. Other efforts will focus on the implementation of a functionality to handle the remapping of emissions to unstructured destination grids (e.g. octahedral grid), which are starting to be widely used in global models due to their computational efficiency and effective resolution, as well as on the inclusion of sectordependent spatial proxies during the remapping process and the improvement of the scalability of the writing function.

Code availability. The HERMESv3_GR code package, preprocessing functions to homogenize the emission inventories (listed in Table 1), sample configuration and ancillary input files (vertical, temporal and speciation profiles), and test case data are available at the following gitlab repository: https://earth.bsc.es/gitlab/es/hermesv3_gr (last access: May 2019). A wiki of the processing system with further instructions is also included in the gitlab repository, as well as the links and references for downloading and citing the original gridded emission inventories that HERMESv3_GR can process. The required libraries need to be installed by the user in the computer infrastructure on which the processing system is planned to be run. 


\section{Appendix A}

Table A1. HERMESv3_GR general configuration file (hermes.conf).

\begin{tabular}{|c|c|}
\hline Parameters and examples & Description and comments \\
\hline \multicolumn{2}{|l|}{ General } \\
\hline log_level $=3$ & $\begin{array}{l}\text { Defines the logging level, which is associated with the amount of information that } \\
\text { will appear in the log file. The options are } 1,2 \text { or } 3 \text { (recommended for debugging) }\end{array}$ \\
\hline 〉input_dir = /gpfs/projects/HERMESv3/IN & Defines the general input directory of the model \\
\hline data_path $=/$ gpfs/scratch/data/ & $\begin{array}{l}\text { Defines the common directory path where all the homogenized emission inventories } \\
\text { used by HERMESv3_GR are stored. The complete path to each specific emission } \\
\text { inventory file is specified in the emission inventory configuration file }\end{array}$ \\
\hline 〉output_dir=/gpfs/projects/HERMESv3/OUT & Defines the directory where the output emission files will be stored \\
\hline$\rangle$ output_name $=$ HERMESv3_〈date $\rangle. n c$ & $\begin{array}{l}\text { Name of the output emission file. The string }\langle\text { date }\rangle \text { is automatically replaced by } \\
\text { the starting date of the simulation day. The complete path to the output file is the } \\
\text { combination of output_dir and output_name. }\end{array}$ \\
\hline$\rangle$ start_date $=2010 / 01 / 01$ 00:00:00 & $\begin{array}{l}\text { Starting date of the simulation (in UTC). Date formats accepted by HER- } \\
\text { MESv3_GR include } \\
\text { - YYYYMMDD: } 20150101 \\
\text { - YYYYMMDDhh: } 2015010100 \\
\text { - YYYYYMMDD.hh: } 20150101.00 \\
\text { - YYYY/MM/DD: } 2015 / 01 / 01 \\
\text { - YYYY/MM/DD_hh: 2015/01/01_00 } \\
\text { - YYYY/MM/DD_hh:mm:ss: 2015/01/01_00:00:00 } \\
\text { - YYYY/MM/DD hh:mm:ss: 2015/01/01 00:00:00 } \\
\text { - YYYY-MM-DD_hh: 2015-01-01_00 } \\
\text { - YYYY-MM-DD_hh:mm:ss: 2015-01-01_00:00:00 } \\
\text { - YYYY-MM-DD hh:mm:ss: 2015-01-0100:00:00. }\end{array}$ \\
\hline >end_date $=2010 / 01 / 02$ 00:00:00 & $\begin{array}{l}\text { Optional: ending date of the simulation (in UTC). If it is not set, then } \\
\text { end_date = start_date. }\end{array}$ \\
\hline 〉output_timestep_type $=$ hourly & $\begin{array}{l}\text { Temporal resolution of the output file. The options are } \\
\text { - hourly } \\
\text { - daily } \\
\text { - monthly. }\end{array}$ \\
\hline >output_timestep_num $=24$ & Number of time steps to simulate \\
\hline output_timestep_freq $=1$ & Frequency between time steps \\
\hline \multicolumn{2}{|l|}{ Domain } \\
\hline output_model = CMAQ & $\begin{array}{l}\text { Defines the format of the output emission file as a function of the atmospheric chem- } \\
\text { istry model conventions. Current options are } \\
\text { - MONARCH } \\
\text { - CMAQ } \\
\text { - WRF_CHEM. }\end{array}$ \\
\hline output_attributes $=\langle$ input_dir $\rangle /$ data/cmaq_global_attributes.csv & $\begin{array}{l}\text { Path to the file that contains the global attributes that need to be included in the } \\
\text { output NetCDF file according to the corresponding chemical transport model }\end{array}$ \\
\hline domain_type $=1 \mathrm{lcc}$ & $\begin{array}{l}\text { Defines the grid projection on which the emission fields will be generated. Options } \\
\text { are as follows. } \\
\text { - Global: regular lat-long grid } \\
\text { - Rotated: rotated lat-long grid } \\
\text { - lcc: Lambert conformal conic grid } \\
\text { - Mercator: Mercator grid. }\end{array}$ \\
\hline vertical_description $=\langle$ input_dir $\rangle /$ data/profiles/vertical/vert.csv & Path to the file that contains the vertical description of the desired output \\
\hline aux_files_path $=\langle$ input_dir $\rangle /$ data/aux_files $/\langle$ domain_type $\rangle \_\langle\text {res }\rangle$ & $\begin{array}{l}\text { Path to the directory where the necessary auxiliary files (e.g. time zones file) will } \\
\text { be created if they do not exist. If they already exist, HERMESv3_GR will just read } \\
\text { them. }\end{array}$ \\
\hline \# if domain_type $==$ global: & Parameters that define a global regular lat-long grid: \\
\hline inc_lat $=0.5$ & - inc_lat: latitudinal grid resolution (degrees) \\
\hline inc_long $=0.703125$ & - inc_long: longitudinal grid resolution (degrees). \\
\hline$\#$ if domain_type $==$ rotated: & Parameters that define a regional rotated lat-long grid: \\
\hline centre_lat $=35$ & - centre_lat $=$ central geographic latitude of the grid (non-rotated degrees) \\
\hline centre_long $=20$ & - centre_long $=$ central geographic longitude of grid (non-rotated degrees, positive \\
\hline west_boundary $=-51$ & east) \\
\hline south_boundary $=-35$ & - west_boundary = grid’s western boundary from centre point (rotated degrees) \\
\hline inc_rlat $=0.1$ & - south_boundary = grid's southern boundary from centre point (rotated degrees) \\
\hline inc_rlon $=0.1$ & $\begin{array}{l}\text { - inc_rlat }=\text { latitudinal grid resolution (rotated degrees) } \\
\text { - inc_rlon }=\text { longitudinal grid resolution (rotated degrees) }\end{array}$ \\
\hline
\end{tabular}


Table A1. Continued.

\begin{tabular}{|c|c|}
\hline Parameters and examples & Description and comments \\
\hline \multicolumn{2}{|l|}{ Domain } \\
\hline $\begin{array}{l}\# \text { if domain_type }==1 c c: \\
\text { lat_1 }=37 \\
\text { lat_2 }=43 \\
\text { long_0 }=-3 \\
\text { lat_0 }=40 \\
n x=278 \\
\text { ny }=298 \\
\text { inc_x }=1000 \\
\text { inc_y }=1000 \\
x \_0=253151.59375 \\
y \_0=43862.90625 \\
\# \text { if domain_type }==\text { Mercator: } \\
\text { lat_ts }=-2.84 \\
\text { long_0 }=-79.16 \\
\text { nx }=99 \\
\text { ny }=81 \\
\text { inc_x }=1000 \\
\text { inc_y }=1000 \\
x \_0=-49500.13899 \\
y \_0=-355986.692\end{array}$ & $\begin{array}{l}\text { Parameters that define a regional Lambert conformal conic grid: } \\
\text { lat_1 }=\text { standard parallel } 1 \text { (in degrees). } \\
\text { lat_2 }=\text { standard parallel } 2 \text { (in degrees). } \\
\text { long_0 }=\text { longitude of the central meridian (in degrees). } \\
\text { lat_0 }=\text { latitude of the origin of the projection (in degrees). } \\
\mathrm{nx}=\text { number of grid columns. } \\
\mathrm{ny}=\text { number of grid rows. } \\
\text { inc_x }=x \text {-coordinate cell dimension (in metres). } \\
\text { inc_y }=y \text {-coordinate cell dimension (in metres). } \\
\mathrm{x} \_0=x \text {-coordinate origin of grid (in metres). } \\
\mathrm{y} \_0=y \text {-coordinate origin of grid (in metres). } \\
\text { Parameters that define a regional Lambert conformal conic grid: } \\
\text { lat_ts }=\text { latitude of true scale (in degrees). } \\
\text { long_0 }=\text { longitude of projection centre (in degrees). } \\
\mathrm{nx}=\text { number of grid columns. } \\
\text { ny }=\text { number of grid rows. } \\
\text { inc_x }=x \text {-coordinate cell dimension (in metres). } \\
\text { inc_y }=y \text {-coordinate cell dimension (in metres). } \\
\mathrm{x} \_0=x \text {-coordinate origin of grid (in metres). } \\
\mathrm{y} \_0=y \text {-coordinate origin of grid (in metres). }\end{array}$ \\
\hline \multicolumn{2}{|l|}{ emission_inventory_configuration } \\
\hline cross_table $=\langle$ input_dir $\rangle /$ conf/EI_conf.csv & Defines the path to the emission inventory configuration file \\
\hline \multicolumn{2}{|l|}{ emission_inventory_profiles } \\
\hline $\begin{array}{l}\text { p_vertical }=\langle\text { input_dir }\rangle / \text { data/profiles/vertical/vert_prof.csv } \\
\text { p_month }=\langle\text { input_dir }\rangle / \text { data/profiles/temporal/month.csv } \\
\text { p_day }=\langle\text { input_dir }\rangle / \text { data/profiles/temporal/day.csv } \\
\text { p_hour }=\langle\text { input_dir }\rangle / \text { data/profiles/temporal/hour.csv } \\
\text { p_speciation }=\langle\text { input_dir }\rangle / \text { data/profiles/speciation/spec_cb05aero5.csv } \\
\text { molecular_weights }=\langle\text { input_dir }\rangle / \text { data/profiles/speciation/MW.csv } \\
\text { world_info }=\langle\text { input_dir }\rangle / \text { data/profiles/temporal/tz_iso3166.csv }\end{array}$ & $\begin{array}{l}\text { Defines the path to the file that contains the vertical profiles. } \\
\text { Defines the path to the file that contains the monthly temporal profiles. } \\
\text { Defines the path to the file that contains the daily temporal profiles. } \\
\text { Defines the path to the file that contains the hourly temporal profiles. } \\
\text { Defines the path to the file that contains the speciation profiles. } \\
\text { Defines the path to the file that contains the molecular weights of the input pollutant } \\
\text { species. } \\
\text { Defines the path to the file that contains the mapping between worldwide time zones } \\
\text { and country ISO3 codes. This file is used to create the time zone grid for the tem- } \\
\text { poral disaggregation of the emissions. }\end{array}$ \\
\hline
\end{tabular}

Table A2. Description of the species included in the CB05, RADM2, AERO5 and MADE-SORGAM chemical mechanisms.

\begin{tabular}{lll}
\hline Chemical mechanism & Species & Description \\
\hline CB05 & ALD2 & Acetaldehyde \\
ALDX & C3+ aldehydes \\
BENZENE & Benzene \\
CO & Carbon monoxide \\
ETH & Ethene \\
ETHA & Ethane \\
ETOH & Ethanol \\
FORM & Formaldehyde and parts of molecules that rapidly form formaldehyde \\
HONO & Nitrous acid \\
IOLE & Internal olefin carbon bond $(\mathrm{R}-\mathrm{C}=\mathrm{C}-\mathrm{R})$ \\
ISOP & Isoprene \\
MEOH & Methanol \\
NH3 & Ammonia \\
NO & Nitric oxide \\
NO2 & Nitrogen dioxide \\
OLE & Terminal olefin bond $(\mathrm{R}-\mathrm{C}=\mathrm{C})$ \\
PAR & Paraffin carbon bond $(\mathrm{C}-\mathrm{C})$ \\
\hline
\end{tabular}


Table A2. Continued.

\begin{tabular}{|c|c|c|}
\hline Chemical mechanism & Species & Description \\
\hline \multirow[t]{6}{*}{ CB05 } & SESQ & Sesquiterpene \\
\hline & $\mathrm{SO} 2$ & Sulfur dioxide \\
\hline & SULF & Sulfuric acid gas \\
\hline & TERP & Terpenes \\
\hline & TOL & Toluene and other monoalkyl aromatics \\
\hline & XYL & Xylene and other polyalkyl aromatics \\
\hline \multirow[t]{20}{*}{ RADM2 } & ALD & Higher aldehydes \\
\hline & $\mathrm{CO}$ & Carbon monoxide \\
\hline & ETH & Ethane \\
\hline & $\mathrm{HC} 3$ & Propane \\
\hline & HC5 & Alkanes $(0.50-1.00)$ \\
\hline & $\mathrm{HC} 8$ & Alkanes (1.00-2.00) \\
\hline & $\mathrm{HCHO}$ & Formaldehyde \\
\hline & ISO & Isoprene \\
\hline & KET & Ketones \\
\hline & $\mathrm{NH} 3$ & Ammonia \\
\hline & NO & Nitric oxide \\
\hline & $\mathrm{NO} 2$ & Nitrogen dioxide \\
\hline & OL2 & Ethene \\
\hline & OLI & Alkenes (internal) \\
\hline & OLT & Propene \\
\hline & ORA1 & Formic acid \\
\hline & ORA2 & Organic acids \\
\hline & $\mathrm{SO} 2$ & Sulfur dioxide \\
\hline & TOL & Toluene \\
\hline & XYL & Xylenes and higher aromatics \\
\hline \multirow[t]{6}{*}{ AERO5 } & POA & Primary organic aerosols \\
\hline & PEC & Primary elemental carbon \\
\hline & PNO3 & Primary nitrate fine \\
\hline & PSO4 & Primary sulfate fine \\
\hline & PMFINE & Primary others fine \\
\hline & PMC & Coarse particulate matter \\
\hline \multirow[t]{11}{*}{ MADE-SORGAM } & PM_10 & Unspeciated primary $\mathrm{PM}_{10}$ \\
\hline & PM25J & Unspeciated primary $\mathrm{PM}_{2.5}$ accumulation mode \\
\hline & PM25I & Unspeciated primary $\mathrm{PM}_{2.5}$ nuclei mode \\
\hline & ECJ & Elemental carbon $\mathrm{PM}_{2.5}$ accumulation mode \\
\hline & ECI & Elemental carbon $\mathrm{PM}_{2.5}$ nuclei mode \\
\hline & ORGJ & Organic carbon $\mathrm{PM}_{2.5}$ accumulation mode \\
\hline & ORGI & Organic carbon $\mathrm{PM}_{2.5}$ nuclei mode \\
\hline & NO3J & Nitrate $\mathrm{PM}_{2.5}$ accumulation mode \\
\hline & NO3I & Nitrate $\mathrm{PM}_{2.5}$ nuclei mode \\
\hline & SO4J & Sulfate $\mathrm{PM}_{2.5}$ accumulation mode \\
\hline & SO4I & Sulfate $\mathrm{PM}_{2.5}$ nuclei mode \\
\hline
\end{tabular}


Author contributions. MG conceived and coordinated the development of HERMESv3_GR, prepared all the input databases (vertical, temporal and speciation profiles) and selected the inventories to be included in the emission data library. MP helped preparing the input databases and perform software tests. CT developed the HERMESv3_GR code and ran the experiments to test the performance of the parallel implementation. OJ helped conceive HERMESv3_GR and its implementation within NMMB-MONARCH. CPGP helped conceiving HERMESv3_GR and supervised the work. MG prepared the paper with contributions from all co-authors.

Competing interests. The authors declare that they have no conflict of interest.

Acknowledgements. The research leading to these results has received funding from the Ministerio de Economía y Competitividad (MINECO) as part of the PAISA project CGL2016-75725-R and the NUTRIENT project CGL2017-88911-R. The authors acknowledge PRACE for awarding access to Marenostrum4 based in Spain at the Barcelona Supercomputing Center through the Tier-0 HHRNTCP and Tier-0 EEDMC projects. Carlos Pérez García-Pando acknowledges long-term support from the AXA Research Fund, as well as the support received through the Ramón y Cajal programme (grant RYC-2015-18690) of the Spanish Ministry of Economy and Competitiveness. The authors would also like to thank the two anonymous referees for their thorough comments, which helped improve the quality of the paper.

Review statement. This paper was edited by Augustin Colette and reviewed by two anonymous referees.

\section{References}

Ackermann, I. J., Hass, H., Memmsheimer, M., Ebel, A., Binkowski, F. S., and Shankar, U.: Modal aerosol dynamics model for Europe: development and first applications, Atmos. Environ., 32, 2981-2999, https://doi.org/10.1016/S13522310(98)00006-5, 1998.

Appel, K. W., Napelenok, S. L., Foley, K. M., Pye, H. O. T., Hogrefe, C., Luecken, D. J., Bash, J. O., Roselle, S. J., Pleim, J. E., Foroutan, H., Hutzell, W. T., Pouliot, G. A., Sarwar, G., Fahey, K. M., Gantt, B., Gilliam, R. C., Heath, N. K., Kang, D., Mathur, R., Schwede, D. B., Spero, T. L., Wong, D. C., and Young, J. O.: Description and evaluation of the Community Multiscale Air Quality (CMAQ) modeling system version 5.1, Geosci. Model Dev., 10, 1703-1732, https://doi.org/10.5194/gmd-10-1703-2017, 2017.

Badia, A., Jorba, O., Voulgarakis, A., Dabdub, D., Pérez GarcíaPando, C., Hilboll, A., Gonçalves, M., and Janjic, Z.: Description and evaluation of the Multiscale Online Nonhydrostatic AtmospheRe CHemistry model (NMMB-MONARCH) version 1.0: gas-phase chemistry at global scale, Geosci. Model Dev., 10, 609-638, https://doi.org/10.5194/gmd-10-609-2017, 2017.

Baldasano, J. M., Guereca, L. P., Lopez, E., Gasso, S., and JimenezGuerrero, P.: Development of a high-resolution $(1 \mathrm{~km} \times 1 \mathrm{~km}$,
$1 \mathrm{~h}$ ) emission model for Spain: The high-elective resolution modelling emission system (HERMES), Atmos. Environ. 42, 72157233, https://doi.org/10.1016/j.atmosenv.2008.07.026, 2008.

Baldasano, J. M., Goncalves, M., Soret, A., and JimenezGuerrero, P.: Air pollution impacts of speed limitation measures in large cities: The need for improving traffic data in a metropolitan Area, Atmos. Environ., 44, 2997-3006, https://doi.org/10.1016/j.atmosenv.2010.05.013, 2010.

Bieser, J., Aulinger, A., Matthias, V., Quante, M., and Denier van der Gon, H.: Vertical emission profiles for Europe based on plume rise calculations., Environ. Pollut., 159, 2935-2946, https://doi.org/10.1016/j.envpol.2011.04.030, 2011.

Borge, R., Lumbreras, J., Pérez, J., de la Paz, D., Vedrenne, M., de Andrés, J. M., and Rodríguez, M. E.: Emission inventories and modeling requirements for the development of air quality plans. Application to Madrid (Spain), Sci. Total Environ., 466-467, 809-819, https://doi.org/10.1016/j.scitotenv.2013.07.093, 2014

Burling, I. R., Yokelson, R. J., Griffith, D. W. T., Johnson, T. J., Veres, P., Roberts, J. M., Warneke, C., Urbanski, S. P., Reardon, J., Weise, D. R., Hao, W. M., and de Gouw, J.: Laboratory measurements of trace gas emissions from biomass burning of fuel types from the southeastern and southwestern United States, Atmos. Chem. Phys., 10, 11115-11130, https://doi.org/10.5194/acp-10-11115-2010, 2010.

Carn, S. A., Fioletov, V. E., McLinden, C. A., Li, C., and Krotkov, N. A.: A decade of global volcanic $\mathrm{SO}_{2}$ emissions measured from space, Sci. Rep.-UK, 7, 44095, https://doi.org/10.1038/srep44095, 2017.

Carter, W. P. L.: Development of a database for chemical mechanism assignments for volatile organic emissions, J. Air Waste Manage., 65, 1171-1184, https://doi.org/10.1080/10962247.2015.1013646, 2015.

Crippa, M., Guizzardi, D., Muntean, M., Schaaf, E., Dentener, F., van Aardenne, J. A., Monni, S., Doering, U., Olivier, J. G. J., Pagliari, V., and Janssens-Maenhout, G.: Gridded emissions of air pollutants for the period 1970-2012 within EDGAR v4.3.2, Earth Syst. Sci. Data, 10, 1987-2013, https://doi.org/10.5194/essd-10-1987-2018, 2018.

Denier van der Gon, H. A. C., Hendriks, C., Kuenen, J., Segers, A., and Visschedijk, A. J. H.: Description of current temporal emission patterns and sensitivity of predicted AQ for temporal emission patterns, EU FP7 MACC deliverable report D_D-EMIS_1.3, 2011.

Ferreira, J., Guevara, M., Baldasano, J. M., Tchepel, O., Schaap, M., Miranda, A. I., and Borrego, C.: A comparative analysis of two highly spatially resolved European atmospheric emission inventories, Atmos. Environ. 75, 43-57, https://doi.org/10.1016/j.atmosenv.2013.03.052, 2013.

Freitas, S. R., Longo, K. M., Alonso, M. F., Pirre, M., Marecal, V., Grell, G., Stockler, R., Mello, R. F., and Sánchez Gácita, M.: PREP-CHEM-SRC - 1.0: a preprocessor of trace gas and aerosol emission fields for regional and global atmospheric chemistry models, Geosci. Model Dev., 4, 419-433, https://doi.org/10.5194/gmd-4-419-2011, 2011.

Friedrich, R. and Reis, S. (Eds.): Emissions of air pollutants - measurements, calculations and uncertainties, GENEMIS, EUROTRAC-2 subproject final report, Springer Verlag, Berlin, Heidelberg, New York, 2004. 
Frost, G. J., Middleton, P., Tarrasón, L., Granier, C., Guenther, A., Cardenas, B., Denier van der Gon, H. A. C., Janssens-Maenhout, G., Kaiser, J. W., Keating, T., Klimont, Z., Lamarque, J.-F., Liousse, C., Nickovic, S., Ohara, T., Schultz, M. G., Skiba, U., van Aardenne, J., and Wang, Y.: New Directions: GEIA's 2020 vision for better air emissions information, Atmos. Environ., 81, 710-712, https://doi.org/10.1016/j.atmosenv.2013.08.063, 2013.

Granier, C., Bessagnet, B., Bond, T., D’Angiola, A., Denier van der Gon, H., Frost, G., Heil, A., Kaiser, J., Kinne, S., Klimont, Z., Kloster, S., Lamarque, J.-F., Liousse, C., Masui, T., Meleux, F., Mieville, A., Ohara, T., Raut, J.-C., Riahi, K., Schultz, M., Smith, S., Thompson, A., Aardenne, J., Werf, G., and Vuuren, D.: Evolution of anthropogenic and biomass burning emissions of air pollutants at global and regional scales during the 1980-2010 period, Climatic Change, 109, 163-190, https://doi.org/10.1007/s10584-011-0154-1, 2011.

Grell, G., Peckham, S., Schmitz, R., McKeen, S., Frost, G., Skamarock, W. C., and Eder, B.: Fully coupled "online" chemistry within the WRF model, Atmos. Environ., 39, 6957-6975, https://doi.org/10.1016/j.atmosenv.2005.04.027, 2005.

Guenther, A. B., Jiang, X., Heald, C. L., Sakulyanontvittaya, T., Duhl, T., Emmons, L. K., and Wang, X.: The Model of Emissions of Gases and Aerosols from Nature version 2.1 (MEGAN2.1): an extended and updated framework for modeling biogenic emissions, Geosci. Model Dev., 5, 1471-1492, https://doi.org/10.5194/gmd-5-1471-2012, 2012.

Guevara, M., Martínez, F., Arévalo, G., Gassó, S., and Baldasano, J. M.: An improved system for modelling Spanish emissions: HERMESv2.0, Atmos. Environ., 81, 209-221, https://doi.org/10.1016/j.atmosenv.2013.08.053, 2013.

Guevara, M., Pay, M. T., Martínez, F., Soret, A., Denier van der Gon, H. A. C., and Baldasano, J. M.: Inter-comparison between HERMESv2.0 and TNO-MACC-II emission data using the CALIOPE air quality system (Spain), Atmos. Environ., 98, 134-145, https://doi.org/10.1016/j.atmosenv.2014.08.067, 2014.

Guevara, M., Tena, C., Soret, A., Serradell, K., Guzmán, D., Retama, A., Camacho, P., Jaimes-Palomera, M., and Mediavilla, A.: An emission processing system for air quality modelling in the Mexico City metropolitan area: Evaluation and comparison of the MOBILE6.2-Mexico and MOVESMexico traffic emissions, Sci. Total Environ., 584-585, 882-900, https://doi.org/10.1016/j.scitotenv.2017.01.135, 2017.

Guevara, M., et al.: HERMESv3, a stand-alone multiscale atmospheric emission modelling framework - Part 2: bottom-up module, in preparation, 2019.

Hill, C., DeLuca, C., Balaji, V., Suarez, M., and Silva, A. D.: The Architecture of the Earth System Modeling Framework, Comput. Sci. Eng., 6, 18-28, https://doi.org/10.1109/MCISE.2004.1255817, 2004.

Hodzic, A., Wiedinmyer, C., Salcedo, D., and Jimenez, J. L.: Impact of Trash Burning on Air Quality in Mexico City, Environ. Sci. Technol., 46, 4950-4957, https://doi.org/10.1021/es203954r, 2012.

Hoesly, R. M., Smith, S. J., Feng, L., Klimont, Z., JanssensMaenhout, G., Pitkanen, T., Seibert, J. J., Vu, L., Andres, R. J., Bolt, R. M., Bond, T. C., Dawidowski, L., Kholod, N., Kurokawa, J.-I., Li, M., Liu, L., Lu, Z., Moura, M. C. P., O'Rourke, P. R., and Zhang, Q.: Historical (1750-2014) anthropogenic emissions of reactive gases and aerosols from the Com- munity Emissions Data System (CEDS), Geosci. Model Dev., 11 369-408, https://doi.org/10.5194/gmd-11-369-2018, 2018.

Houyoux, M. R., Vukovich, J. M., Coats, C. J., Wheeler, N. J. M., and Kasibhatla, P. S.: Emission inventory development and processing for the Seasonal Model for Regional Air Quality (SMRAQ) project, J. Geophys. Res.-Atmos., 105, 9079-9090, https://doi.org/10.1029/1999JD900975, 2000.

Huang, G., Brook, R., Crippa, M., Janssens-Maenhout, G., Schieberle, C., Dore, C., Guizzardi, D., Muntean, M., Schaaf, E., and Friedrich, R.: Speciation of anthropogenic emissions of non-methane volatile organic compounds: a global gridded data set for 1970-2012, Atmos. Chem. Phys., 17, 7683-7701, https://doi.org/10.5194/acp-17-7683-2017, 2017.

Janssens-Maenhout, G., Crippa, M., Guizzardi, D., Dentener, F., Muntean, M., Pouliot, G., Keating, T., Zhang, Q., Kurokawa, J., Wankmüller, R., Denier van der Gon, H., Kuenen, J. J. P., Klimont, Z., Frost, G., Darras, S., Koffi, B., and Li, M.: HTAP_v2.2: a mosaic of regional and global emission grid maps for 2008 and 2010 to study hemispheric transport of air pollution, Atmos. Chem. Phys., 15, 11411-11432, https://doi.org/10.5194/acp-15-11411-2015, 2015.

Kaiser, J. W., Heil, A., Andreae, M. O., Benedetti, A., Chubarova, N., Jones, L., Morcrette, J.-J., Razinger, M., Schultz, M. G., Suttie, M., and van der Werf, G. R.: Biomass burning emissions estimated with a global fire assimilation system based on observed fire radiative power, Biogeosciences, 9, 527-554, https://doi.org/10.5194/bg-9-527-2012, 2012.

Keller, C. A., Long, M. S., Yantosca, R. M., Da Silva, A. M., Pawson, S., and Jacob, D. J.: HEMCO v1.0: a versatile, ESMF-compliant component for calculating emissions in atmospheric models, Geosci. Model Dev., 7, 1409-1417, https://doi.org/10.5194/gmd-7-1409-2014, 2014.

Klimont, Z., Kupiainen, K., Heyes, C., Purohit, P., Cofala, J., Rafaj, P., Borken-Kleefeld, J., and Schöpp, W.: Global anthropogenic emissions of particulate matter including black carbon, Atmos. Chem. Phys., 17, 8681-8723, https://doi.org/10.5194/acp-178681-2017, 2017.

Kuenen, J. J. P., Visschedijk, A. J. H., Jozwicka, M., and Denier van der Gon, H. A. C.: TNO-MACC_II emission inventory; a multi-year (2003-2009) consistent high-resolution European emission inventory for air quality modelling, Atmos. Chem. Phys., 14, 10963-10976, https://doi.org/10.5194/acp-14-109632014, 2014.

López-Aparicio, S., Guevara, M., Thunis, P., Cuvelier, K., and Tarrason, L.: Assessment of discrepancies between bottom-up and regional emission inventories in Norwegianurban areas, Atmos. Environ., 154, 285-296, https://doi.org/10.1016/j.atmosenv.2017.02.004, 2017.

Luderer, G., Trentmann, J., Winterrath, T., Textor, C., Herzog, M., Graf, H. F., and Andreae, M. O.: Modeling of biomass smoke injection into the lower stratosphere by a large forest fire (Part II): sensitivity studies, Atmos. Chem. Phys., 6, 5261-5277, https://doi.org/10.5194/acp-6-5261-2006, 2006.

Mailler, S., Khvorostyanov, D., and Menut, L.: Impact of the vertical emission profiles on background gas-phase pollution simulated from the EMEP emissions over Europe, Atmos. Chem. Phys., 13, 5987-5998, https://doi.org/10.5194/acp-135987-2013, 2013. 
Mareckova, K., Pinterits, M., Ullrich, B., Wankmueller, R., and Mandl, N.: Inventory review 2017. Review of emission data reported under the LRTAP Convention and the NEC Directive Stage 1 and 2 review, Status of gridded and LPS data, Technical Report CEIP 2/2017, Umweltbundesamt GmbH, Vienna, 2017.

Mues, A., Kuenen, J., Hendriks, C., Manders, A., Segers, A., Scholz, Y., Hueglin, C., Builtjes, P., and Schaap, M.: Sensitivity of air pollution simulations with LOTOS-EUROS to the temporal distribution of anthropogenic emissions, Atmos. Chem. Phys., 14, 939-955, https://doi.org/10.5194/acp-14-939-2014, 2014.

Olivier, J. G. J., Bouwman, A. F., van der Maas, C. W. M., Berdowski, J. J. M., Veldt, C., Bloos, J. P. J., Visschedijk, A. J. H., Zandveld, P. Y. J., and Haverlag, J. L.: Description of EDGAR Version 2.0: A set of global emission inventories of greenhouse gases and ozone-depleting substances for all anthropogenic and most natural sources on a per country basis and on $1^{\circ} \times 1^{\circ}$ grid, Report no. 771060002/TNO-MEP report no. R96/119, National Institute of Public Health and the Environment (RIVM), Bilthoven, 1996.

Olsen, S. C., Wuebbles, D. J., and Owen, B.: Comparison of global 3-D aviation emissions datasets, Atmos. Chem. Phys., 13, 429441, https://doi.org/10.5194/acp-13-429-2013, 2013.

Paugam, R., Wooster, M., Atherton, J., Freitas, S. R., Schultz, M. G., and Kaiser, J. W.: Development and optimization of a wildfire plume rise model based on remote sensing data inputs - Part 2, Atmos. Chem. Phys. Discuss., 15, 9815-9895, https://doi.org/10.5194/acpd-15-9815-2015, 2015.

Paulot, F., Jacob, D. J., Pinder, R. W., Bash, J. O., Travis, K., and Henze, D. K.: Ammonia emissions in the United States, European Union, and China derived by highresolution inversion of ammonium wet deposition data: interpretation with a new agricultural emissions inventory (MASAGE_NH3), J. Geophys. Res.-Atmos., 119, 4343-4364, https://doi.org/10.1002/2013JD021130, 2014.

Pérez, C., Haustein, K., Janjic, Z., Jorba, O., Huneeus, N., Baldasano, J. M., Black, T., Basart, S., Nickovic, S., Miller, R. L., Perlwitz, J. P., Schulz, M., and Thomson, M.: Atmospheric dust modeling from meso to global scales with the online NMMB/BSC-Dust model - Part 1: Model description, annual simulations and evaluation, Atmos. Chem. Phys., 11, 1300113027, https://doi.org/10.5194/acp-11-13001-2011, 2011.

Pernigotti, D., Belis, C. A., and Spanò, L.: SPECIEUROPE: The European data base for PM source profiles, Atmos. Pollut. Res., 7, 307-314, https://doi.org/10.1016/j.apr.2015.10.007, 2016.

Pouliot, G., Denier van der Gon, H. A. D., Kuenen, J., Zhang, J., Moran, M. D., and Makar, P. A.: Analysis of the emission inventories and model-ready emission datasets of Europe and North America for phase 2 of the AQMEII project, J. Atmos. Environ., 115, 345-360, https://doi.org/10.1016/j.atmosenv.2014.10.061, 2015.

Rappenglueck, B., Lubertino,G., Alvarez, S., Golovko, J., Czader, B., and Ackermann, L.: Radical precursors and related species from traffic as observed and modeled at an urban highway junction, J. Air Waste Manage., 63, 1270-1286, https://doi.org/10.1080/10962247.2013.822438, 2013.

Reff, A., Bhave, P. V., Simon, H., Pace, T. G., Pouliot, G. A., Mobley, J. D., and Houyoux, M.: Emissions inventory of $\mathrm{PM}_{2.5}$ trace elements across the United States, Environ. Sci. Technol., 43, 5790-5796, https://doi.org/10.1021/es802930x, 2009.
Roselle, S. J., Appel, K. W., Foley, K. M., Bhave, P. V., Pleim, J. E., Mathur, R., Otte, T. L., Gilliam, R. C., Sarwar, G., Nolte, C. G., Gililand, A. B., Pinder, R. W., and Swall, J. L.: Incremental testing of updates to the Community Multiscale Air Quality (CMAQ) modeling system version 4.7, the 7th Annual CMAS conference, 6-8 October 2008, Chapel Hill, NC, USA, 2008.

Saikawa, E., Kim, H., Zhong, M., Avramov, A., Zhao, Y., JanssensMaenhout, G., Kurokawa, J.-I., Klimont, Z., Wagner, F., Naik, V., Horowitz, L. W., and Zhang, Q.: Comparison of emissions inventories of anthropogenic air pollutants and greenhouse gases in China, Atmos. Chem. Phys., 17, 6393-6421, https://doi.org/10.5194/acp-17-6393-2017, 2017.

Schell, B., Ackermann, I. J., Hass, H., Binkowski, F. S., and Ebel, A.: Modeling the formation of secondary organic aerosol within a comprehensive air quality model system, J. Geophys. Res.-Atmos., 106, 28275-28293, https://doi.org/10.1029/2001JD000384, 2001.

Schultz, M. G., Backman, L., Balkanski, Y., Bjoerndalsaeter, S., Brand, R., Burrows, J. P., Dalsoeren, S., de Vasconcelos, M., Grodtmann, B., Hauglustaine, D. A., Heil, A., Hoelzemann, J. J., Isaksen, I. S. A., Kaurola, J., Knorr, W., LadstaetterWeißenmayer, A., Mota, B., Oom, D., Pacyna, J., Panasiuk, D., Pereira, J. M. C., Pulles, T., Pyle, J., Rast, S., Richter,A., Savage, N., Schnadt, C., Schulz, M., Spessa, A., Staehelin, J., Sundet, J. K., Szopa, S., Thonicke, K., van het Bolscher, M., van Noije, T., van Velthoven, P., Vik, A. F., and Wittrock, F.: Reanalysis of the Tropospheric chemical composition over the past 40 years (RETRO) - a longterm global modeling study of tropospheric chemistry, Final report, edited by: Schultz, M. G., Reports on Earch System Science, 48/2007, Max Planck Institute for Meteorology, Hamburg, Germany, available at: https://www.mpimet.mpg.de/ fileadmin/publikationen/Reports/WEB_BzE_48.pdf (last access: July 2018), 2007.

Simon, H., Beck, L., Bhave, P. V., Divita, F., Hsu, Y., Luecken, D., Mobley, J. D., Pouliot, G. A., Reff, A., Sarwar, G., and Strum, M.: The development and uses of EPA's SPECIATE database, Atmos. Pollut. Res., 1, 196-206, 2010.

Skjøth, C. A., Geels, C., Berge, H., Gyldenkærne, S., Fagerli, H., Ellermann, T., Frohn, L. M., Christensen, J., Hansen, K. M., Hansen, K., and Hertel, O.: Spatial and temporal variations in ammonia emissions - a freely accessible model code for Europe, Atmos. Chem. Phys., 11, 5221-5236, https://doi.org/10.5194/acp-11-5221-2011, 2011.

Snyder, M. G., Venkatram, A., Heist, D. K., Perry, S. G., Petersen, W. B., and Isakov, V.: RLINE: A line source dispersion model for near-surface releases, Atmos. Environ., 77, 748-756, https://doi.org/10.1016/j.atmosenv.2013.05.074, 2013.

Sofiev, M., Vankevich, R., Ermakova, T., and Hakkarainen, J.: Global mapping of maximum emission heights and resulting vertical profiles of wildfire emissions, Atmos. Chem. Phys., 13, 7039-7052, https://doi.org/10.5194/acp-13-7039-2013, 2013.

Soret, A., Guevara, M., and Baldasano, J. M.: The potential impacts of electric vehicles on air quality in the urban areas of Barcelona and Madrid (Spain), Atmos. Environ., 99, 51-63, https://doi.org/10.1016/j.atmosenv.2014.09.048, 2014.

Stockwell, W. R., Middleton, P., Chang, J. S., Tang, X.: The 2nd generation regional acid deposition model chemical mechanism 
for regional air-quality modeling, J. Geophys. Res.-Atmos., 95, 16343-16367, https://doi.org/10.1029/JD095iD10p16343, 1990.

Timmermans, R. M. A., Denier van der Gon, H. A. C., Kuenen, J. J. P., Segers, A. J., Honoré, C., Perrussel, O., Builtjes, P. J. H., and Schaap, M.: Quantification of the urban air pollution increment and its dependency on the use of down-scaled and bottom-up city emission inventories, Urban Climate, 6, 44-62, https://doi.org/10.1016/j.uclim.2013.10.004, 2013.

Trombetti, M., Thunis, P., Bessagnet, B., Clappier, A., Couvidat, F., Guevara, M., Kuenen, J., and López-Aparicio, S.: Spatial inter-comparison of Top-down emission inventories in European urban areas, Atmos. Environ., 173, 142-156, https://doi.org/10.1016/j.atmosenv.2017.10.032, 2018.

Tuccella, P., Curci, G., Visconti, G., Bessagnet, B., Menut, L., and Park, R. J.: Modeling of gas and aerosol with WRF/Chem over Europe: Evaluation and sensitivity study, J. Geophys. Res., 117, D03303, https://doi.org/10.1029/2011JD016302, 2012.

Veira, A., Kloster, S., Schutgens, N. A. J., and Kaiser, J. W.: Fire emission heights in the climate system - Part 2: Impact on transport, black carbon concentrations and radiation, Atmos. Chem. Phys., 15, 7173-7193, https://doi.org/10.5194/acp15-7173-2015, 2015.
Visschedijk, A. J. H., Zandveld, P. Y. J., and Denier van der Gon, H. A. C.: A high resolution gridded European emission database for the EU Integrate Project GEMS, TNO report 2007-A-R0233/B, TNO, Utrecht, the Netherlands, 2007.

Warner, J. X., Dickerson, R. R., Wei, Z., Strow, L. L., Wang, Y., and Liang, Q.: Increased atmospheric ammonia over the world's major agricultural areas detected from space, Geophys. Res. Lett., 44, 2875-2884, https://doi.org/10.1002/2016GL072305, 2017.

Whitten, G. Z., Heo, G., Kimura, Y., McDonald-Buller, E., Allen, D. T., Carter, W. P. L., and Yarwood, G.: A new condensed toluene mechanism for Carbon Bond: CB05-TU, Atmos. Environ., 44, 5346-5355, https://doi.org/10.1016/j.atmosenv.2009.12.029, 2010.

Wiedinmyer, C., Yokelson, R. J., and Gullett, B. K.: Global emissions of trace gases, particulate matter, and hazardous air pollutants from open burning of domestic waste, Environ. Sci. Technol., 48, 9523-9530, https://doi.org/10.1021/es502250z, 2014.

Zhang, L., Chen, Y., Zhao, Y., Henze, D. K., Zhu, L., Song, Y., Paulot, F., Liu, X., Pan, Y., Lin, Y., and Huang, B.: Agricultural ammonia emissions in China: reconciling bottom-up and top-down estimates, Atmos. Chem. Phys., 18, 339-355, https://doi.org/10.5194/acp-18-339-2018, 2018. 